The abstracts are only available online, free of charge, under www.karger.com/doi/10.1159/000076475

\title{
The 9th International Conference on Continuous Renal Replacement Therapies (CRRT)
}

February 26-28, 2004, San Diego, Calif.

\section{Abstracts}

Editor

R.L. Mehta, San Diego, Calif.

\section{Contents}

Patient Characteristics

Emerging Concepts in ARF and CRRT

Abstracts 1-9

Technique Characteristics

Abstracts 10-19

Future Trends

Abstracts 20-32

Author Index 


\section{Patient Characteristics}

\section{1}

\section{Plasma Amino Acids in Critically III Patients}

F. Ruzany, R.A.N. Paiva, C. Valente, J.H. Suassuna, E. Rocha, E. Maccarielo, M.G. Rodrigues

Barra D'or Hospital and University of State of Rio de Janeiro, Rio de Janeiro, Brazil

Introduction: Stress states, sepsis, trauma, markedly increases protein catabolism in skeletal muscle, gut, and connective tissue. Catabolism is potentiate by a sepsis induced decrease in amino acid uptake in skeletal muscle. One-third of the total amino acid output from skeletal muscle is glutamine and one-third is alanine. Objective: Demonstrate the concentration of plasma amino acids in critical ill patients. Materials and Methods: Prospective analysis of 41 patients ( 17 women and 24 men) admitted in a 27 beds intensive care unit (ICU) from July 2002 to May 2003. Twenty-four amino acids were analysed in each patient upto $24 \mathrm{~h}$ of admission in ICU. Amino acids assay, by using high-pressure liquid chromatography (HPLC), were performed by laboratory CTN and Pardini. Results: Patient age average was 73.08 (43 to 88 years) years and APACHE II score was 18.37 (11 to 28 ). Plasma amino acids were obtained in 41 patients and analysed 23 amino acids ( $\mu \mathrm{Mol} / 1)$ : The total value of plasma amino acids was $4,257.475 \mu \mathrm{Mol} / 1$ (average). The dosage of plasma amino acids were as: Aspartic acid - 75.95, Glutamic acid 384.45, Alanine - 587.1, Arginine - 84.45, Asparagine - 78.5, Cystine - 497.55, Phenylalanine - 179.2, Glycine - 497.55, Glutamine - 413.25, Hydroxyproline - 58.25, Histidine - 84.55, Isoleucine -90.325 , Leucine - 195.5, Lysine -190.05 , Methionine 48.85 , Ornithine -118.65 , Proline -201.5 , Serine -156.75 , Taurine 167.25, Tyrosine -127.85 , Threonine -167 , Tryptophan -51.925 , Valine - 278.975. Conclusions: The concentrations of alanine, glutamic acid, aspartic acid, phenylalanine and arginine were more elevated than the others. The glutamine demonstrated to be decreased, probably as an amino acid essential in sepsis or catabolic patients, greatly consumed.

\section{2 \\ Continuous Renal Replacement Therapy (CRRT) in Pediatric Bone Marrow Transplant Patients: Report of Prospective Pediatric Continuous Renal Replacement Therapy (ppCRRT) Registry Group}

F.X. Flores

ppCRRT Registry Group, Houston, Texas, USA

Pediatric bone marrow transplant (BMT) recipients (pts) commonly develop renal dysfunction and many require renal replacement therapy due to electrolyte abnormalities and/or fluid overload (FO). Since 1/1/01, 160 patients from 10 pediatric centers have been enrolled in the ppCRRT Registry. We analyzed demographics and survival data of 22 BMT pts entered in the ppCRRT Registry. Median age was 9.45 years (range 2.2-23.5 years). 20/22 (91\%) pts required ventilatory support. CRRT modalities were CVVHD (45\%), CVVH (41\%) and CVVHDF (14\%). Femoral catheters were used for vascular access in all pts. The most common diagnoses leading to CRRT in these pts were sepsis $(18 \%)$, hepatorenal syndrome (14\%), and multiorgan system failure (14\%). 18\% had no single identifiable diagnosis. The indications to initiate CRRT were FO or prevention of FO (45\%), fluid and electrolyte abnormalities (32\%) and electrolyte abnormalities alone (23\%). 8/22 (36\%) pts survived. Mean time between ICU admission and CRRT initiation for survivors (S) was $10.14 \pm 1.8$ days vs. $15.08 \pm 9.97$ days for non-survivors $(p=0.4)$. Mean CRRT duration was $4.25 \pm 0.62$ days for $\mathrm{S}$ vs. $8.57 \pm 1.66$ days for NS $(\mathrm{p}=0.07)$. S had less FO $(3.75 \pm 2.04 \%$ vs. $16.11 \pm 4.02 \%$, $\mathrm{p}<0.05)$ at CRRT initiation and lower mean airway pressure (MAP) $(11.2 \pm 1.85$ vs. $26.3 \pm 2.86, p=0.0039)$ at the end of CRRT. S and NS were no different with respect to age $(11.22 \pm 2.3$ vs. $10.64 \pm$ 2.35 years, $\mathrm{p}=0.86)$, initial PRISM 2 score $(10.67 \pm 2.35$ vs. $15.62 \pm 2.1, \mathrm{p}=0.17)$, initial MAP $(16.14 \pm 2.25$ vs. $15.5 \pm 2.8$, $\mathrm{p}=0.87)$, GFR $(63.77 \pm 9.21$ vs. $61.52 \pm 14.4, \mathrm{p}=0.89)$, CVP $\left(13.75 \pm 1.89\right.$ vs. $\left.17.23 \pm 1.57 \mathrm{cmH}_{2} \mathrm{O}, \mathrm{p}=0.27\right)$, number of pressors $(1.69 \pm 0.31$ vs. $0.86 \pm 0.4, p=0.12)$, urinary output $(5.09 \pm 3.61$ vs. $1.68 \pm 0.3 \mathrm{cc} / \mathrm{kg} / \mathrm{h}, \mathrm{p}=0.18)$ and total ultrafiltration volume $(52,070 \pm 21,688.03$ vs. $67,384.79 \pm 14,997.83 \mathrm{ml}$, $\mathrm{p}=0.56$ ). We conclude that the BMT cohort of the ppCRRT Registry demonstrated similar survival compared to previous single center studies; S had less fluid overload, lower MAP at the end of CRRT, and tended to require shorter CRRT duration than NS. We speculate 'early' CRRT initiation to prevent worse FO and pulmonary edema may improve survival for pediatric BMT pts and the two-fold longer CRRT duration seen in NS may indicate that increased FO may lead to FO-associated co-morbidity that cannot be rectified by CRRT.

\begin{tabular}{ll}
\hline KARGER & (c) 2004 S. Karger AG, Basel \\
0253-5068/04/0222-0230\$21.00/0 \\
$\begin{array}{l}\text { Fax +4161306 1234 } \\
\text { E-Mail karger@karger.ch } \\
\text { www.karger.com }\end{array}$ & $\begin{array}{l}\text { Accessible online at: } \\
\text { www.karger.com/bpu }\end{array}$
\end{tabular}




\section{3}

\section{Survival and Renal Recovery in ICU Patients Receiving CRRT}

\section{D.T. Plott, T. Yamkokoski, U.Y. Bhatt \\ Ohio State University, Columbus, Ohio, USA}

Acute renal failure (ARF) complicates the course of 5 to $40 \%$ of ICU patients. The overall mortality has remained unchanged despite the advent of renal replacement technologies, including intermittent hemodialysis (iHD) and continuous renal replacement therapy (CRRT). Recent studies have shown no differential benefit between the 2 modalities for patient survival and renal survival. These studies have examined overall ICU survival. However, the influence of diagnosis and underlying illness on survival in patients requiring CRRT support has not been completely defined. Therefore, the objective of this study is to examine survival in ARF patients receiving CRRT in 4 different ICU environments: medical (MICU), surgical (SICU), cardiac (CICU), and bone marrow transplantation (BMT). Retrospective review of 12 months of data revealed 154 ARF patients who received support with CRRT. The main indication for CRRT was renal failure and hemodynamic instability, as assessed by nephrology consultation. The data reviewed included location, survival, and renal recovery prior to hospital discharge. The findings are presented in the table below. Despite cardiovascular instability in all patients, those with cardiac diagnoses had significantly greater survival. In addition, rates of renal recovery were much greater in patients admitted to the medical ICU. Conclusions: These data demonstrate that survival and renal recovery in hemodynamically unstable ARF patients receiving CRRT varies with diagnosis and comorbid illness. The results support the contention that future trials of therapeutic efficacy examine subpopulations based on diagnosis and underlying disease processes.

\begin{tabular}{lllll}
\hline Total patients $=154$ & MICU & SICU & CICU & BMT \\
\hline No. of patients & 86 & 43 & 14 & 11 \\
Survival (\%) & 30.2 & 30.2 & 42.9 & 27.3 \\
Renal recovery (\%) & 75 & 50 & 50 & 0 \\
\hline
\end{tabular}

\section{4 \\ Heparin Induced Thrombocytopenia: Alternative Solutions to Maintain Anticoagulation without Heparin

\author{
S.L. Hughes, A. Macy \\ Clarian Health Partners/IU Hospital, Indianapolis, \\ Indiana, USA
}

Purpose: To present Clarian's solution to alternative Coagulation therapy for Heparin Induced Thrombocytopenia (HIT) for patients receiving Dialysis and Continuous Renal Replacement Therapies (CRRT). Description: HIT is a serious side effect of Heparin therapy. It is becoming more recognized by the medical community and proving to be one of the foremost immunohematologic issues confronting patients receiving Heparin therapy. Common populations of patients receiving Heparin therapy are Dialysis and CRRT patients due to the need to keep the blood in the extracorporial circuits anticoagulated. Adverse side effects of HIT include Deep Vein Thrombosis (DVT), Pulmonary Embolism (PE), Myocardial Infarction (MI), Cerebral Vascular Accident (CVA) and even Death. Solution: Clarian's Solution to HIT utilizes the drugs Argatroban, epoprostenol (Flolan), and lepirudin (Refludan) for Dialysis and CRRT therapies, and Citrate for hemodialysis catheter dwells. Outcomes: Positive outcomes to these alternative coagulation therapies for HIT relate to the negative side effects of HIT. The outcomes measures are: absence of DVT, PE, MI, CVA and Death.

\section{5 \\ Sequential Hemoperfusion and Continuous Veno-Venous Hemofiltration in Treatment of Severely Tetramine Poisoning}

D. Ji, D. Gong, B. Xu, H. Xie, Z. Liu, L. Li

Research Institute of Nephrology, Jinling Hospital، Nanjing University School of Medicine,

Nanjing, P.R. China

Objective: To investigate the therapeutic effects of sequential hemoperfusion (HP) and continuous veno-venous hemofiltration $(\mathrm{CVVH})$ in patients with severe tetramine poisoning, and to evaluate the removal of plasma tetramine by these modalities in these patients. Methodology: Eighteen patients with severe tetramine poisoning (17 in persisting coma, and 15 patients need mechanical ventilation) were treated with HP using activated charcoal for 3-5 h and consecutive CVVH for 24-36h, besides routine medical therapy. APACHE II and Glasgow scores were evaluated daily according to the clinical conditions including blood pressure, heart rate, temperature and consciousness. Blood routine and serum biochemical parameters were also tested and evaluated. Plasma tetramine concentration was determined before and after HP treatment. Tetramine concentration in both pre-filter and post-fiter plasma, and in the ultrafiltrate were also determined at the 2 nd hour and the 12 th hour of CVVH procedure. In HP treatment, 14 patients used 2 adsorbents, and 4 used 1 adsorbent. Results: In the whole patient group, the average APACHE II score declined and average Glasgow score increased after the blood purification procedures. In the 8 patients started these procedures in the first $12 \mathrm{~h}$ after onset of poisoning, 7 recovered completely, and 1 died of cardiac failure. In the 10 patients started $12 \mathrm{~h}$ after onset of poisoning, 6 recovered completely, 2 recovered with mental confusion or decerebral state, and 2 died of circulatory and respiratory failure. Patients with early initiation of HP and CVVH treatment had higher complete recovery rate than those with later initiation of HP and CVVH treatment $(87.5 \%$ vs $60.0 \%, \mathrm{p}<0.05$, c2test). For patients with complete recovery, hours of persisting coma after the initiation of HP and CVVH time were shorter in the early initiation group than those in the later initiation group $[5 \sim 60(23.0 \pm 19.9) \mathrm{h}$ vs $20 \sim 96(59.7 \pm 27.7) \mathrm{h}$, $\mathrm{p}<0.01$, rank test]. In the 14 patients using 2 adsorbents, reduction rate of plasma tetramine after HP was significantly greater than that of patients 1 adsorbent $(42.9 \pm 14.0 \%$ vs $34.7 \pm 13.8 \%, p>0.05)$. Consecutive CVVH were performed in 16 patients. During CVVH, mean plasma tetramine concentration was $0.078 \pm 0.064 \mathrm{mg} / \mathrm{L}$ 
(ultrafiltration sieving coefficient $0.839 \pm 0.409$ ) in the 2 nd hour and $0.074 \pm 0.059 \mathrm{mg} / \mathrm{L}$ in 12 th hour (ultrafiltration sieving coefficient $0.686 \pm 0.253)$. Plasma tetramine concentration at the 2 nd hour of CVVH declined in 15 patients (mean reduction rate $13.2 \pm 12.1 \%$ ), but increased slightly in 1 patient (increasing rate $9.52 \%$ ); at the 12th hour of CVVH, plasma concentration declined in 13 patients (mean reduction rate $29.8 \pm 14.5 \%$ ), but increased slightly in 3 patients (mean increasing rate $11.05 \pm 8.00 \%$ ). Conclusions: Early initiation sequential HP and CVVH treating greatly improved the outcome of severely tetramine poisoning patients. HP can obviously reduce the plasma concentration of tetramine, and CVVH can remove tetramine continuously from the plasma and attenuate the plasma tetramine concentration rebound after HP.

\section{Effects of Continuous High-Volume Hemofiltration on Severe Pulmonary Infection with Acute Respiratory Distress Syndrome in Renal Transplantation Patients}

6

\author{
J. Tao, D. Ji, D. Gong, B. Xu, B. Ren, L. Li \\ Research Institute of Nephrology, Jinling Hospital, \\ Nanjing University School of Medicine, \\ Nanjing, P.R. China
}

Objective: Continuous high-volume hemofiltration (CHVHF) has been reported to be beneficial to patients either with systemic inflammatory response syndrome (SIRS) or with septic shock. This study was to evaluate the effects of CHVHF on severe pulmonary infection with acute respiratory distress syndrome in renal transplantation patients. Methods: Ten renal allograft recipients with severe pulmonary infection were involved, including 9 males and 1 female, with average age $41.4 \pm 11.13(28 \sim 54)$ years. These patients rapidly advanced into acute respiratory distress syndrome (ARDS) after admission and then were treated by CHVHF. CHVHF was carried out continuously for $72 \mathrm{~h}$, with AN69 hemofilter $\left(1.2 \mathrm{~m}^{2}\right)$ and the ultrafiltration (UF) flow rate at $6 \mathrm{~L} / \mathrm{h}$, blood flow rate was $250 \sim 300 \mathrm{ml} / \mathrm{min}$, and the substitute fluid was by a pre-dilution route. Low molecular weight heparin or citrate were used for anticoagulation in CHVHF. The hemofilter was changed to new one every $24 \mathrm{~h}$ except for clotting. Clinical conditions including blood pressure, heart rate and temperature were monitored every 30 minutes, and blood gas analysis, serum C-reactive protein (CRP), IL-6 and IL-10 were detected before and every $12 \mathrm{~h}$ after the initiation of CHVHF. APCHE II scores were evaluated every $12 \mathrm{~h}$ during CHVHF. Results: CHVHF was well tolerated in all patients. Except one patient gave up therapy at $53 \mathrm{~h}$, all of the others had completed 72-hour CHVHF therapy. In these 9 patients, 6 patients died finally (mortality rate 67\%), and 6 patients survived through 15 days after CHVHF (15-days survival rate $67 \%$ ). All patients appeared a steady state of blood pressure and heart rate during CHVHF. Acute renal failure was presented in 8 patients before CHVHF (before CHVHF, Scr $227.5 \pm$ $153.33 \mu \mathrm{mol} / \mathrm{L}$ ), and renal function recovered finally in all patients. Compared with pre-treatment, APCHE II scores were significantly improved at $48 \mathrm{~h}$ of CHVHF $(14.9 \pm 3.46$ vs. pre-treatment $18.1 \pm$ $2.69, \mathrm{p}<0.05)$, and very significantly improved at $60 \mathrm{~h}(14.1 \pm 2.09$, $\mathrm{p}<0.01)$ and at $72 \mathrm{~h}(14.0 \pm 2.69, \mathrm{p}<0.01) . \mathrm{PaO}_{2} / \mathrm{FiO}_{2}$ was found improved in 5 patients after CHVHF, and 4 of them survived. An obvious decrement of serum CRP level was observed at $72 \mathrm{~h}(49.0 \pm$ $33.19 \mathrm{mg} / \mathrm{L}$ vs. pre-treatment $137.0 \pm 56.37 \mathrm{mg} / \mathrm{L}, \mathrm{p}<0.05)$ and at $96 \mathrm{~h}(53.5 \pm 33.8 \mathrm{mg} / \mathrm{L}$ vs. pre-treatment, $\mathrm{p}<0.01)$. IL-6 decreased at $12 \mathrm{~h}(183.6 \pm 259.8 \mathrm{pg} / \mathrm{mL}$ vs. pre-treatment $773.1 \pm 354.9 \mathrm{pg} / \mathrm{ml}$, $\mathrm{p}=0.05)$ and maintained at a steady level during the remaining time of CHVHF. Serum IL-10 level was found little fluctuant during CHVHF. Conclusion: CHVHF therapy can get a survive rate of $44 \%$ and 15 -day survive rate of $67 \%$ in renal transplantation patients with ARDS caused by severe pulmonary infection, and may be beneficial to improving of patients' inflammatory response (reducing serum level of CRP and IL-6).

7 Relative Benefit of Clinical Outcomes in
Continuous Veno-Venous Hemodiafiltration
(CVVHDF) as an Initial Renal Replacement
Therapy after Cardiovascular Surgery J.W. Chang, E.J. Park, W.S. Yang, H. Song1, M.-G. Song ${ }^{1}$, S.K. Lee, S.-K. Park

Departments of Internal Medicine and ${ }^{1}$ Cardiovascular Surgery, Asan Medical Center, University of Ulsan, Seoul, Korea

Background: Although CVVHDF has the hemodynamic stability, an effective volume removal, and a superior metabolic control, previous studies reported no definite reduction of mortality rate by CVVHDF compared to conventional RRT, including hemodialysis (HD) and peritoneal dialysis (PD). We assumed because that they did not analyze the mortality rate under the stratification of disease severity and grouping of specific patients. Objective: We compared the clinical outcomes between CVVHDF and HD/PD as an initial RRT in the patients who had major cardiovascular surgery. Method: We investigated the severity of illness by APACHE III score system at the initiation of RRT and considered the first visit at the out patient clinic after discharge as the patients' survival. Results: In this retrospective study, a total of 88 patients underwent CVVHDF $(\mathrm{N}=48$, $\mathrm{M}: \mathrm{F}=32: 16,58 \pm 11$ years $)$ or $\mathrm{HD} / \mathrm{PD}(\mathrm{N}=40, \mathrm{M}: \mathrm{F}=27: 13,59 \pm$ 10 years). Our data revealed no significant difference in the prevalence of diabetes mellitus, causative cardiovascular disease, operative treatment, renal outcome and overall mortality rate. The overall mortality rate was $27 \%$ in CVVHDF group and $20 \%$ in $\mathrm{HD} / \mathrm{PD}$ group. However, compared with HD/PD group, CVVHDF was applied to more severe patients who had longer median periods with ventilator application (4 days (range 1-105 days) vs. 1 day (range 0-54 days), $\mathrm{p}=0.001$ ), vasopressor use ( 7 days (range $0-41$ days) vs. 3 days (range $0-54$ days), $\mathrm{p}<0.001$ ), ICU admission (12 days (range $2-120$ days) vs. 6 days (range $2-78$ days), $\mathrm{p}=0.004$ ), and higher initial APACHE III scores (74 (range 39-135) vs. 65 (range 39-117), $\mathrm{p}=0.009$ ). Among those with APACHE III scores over 90, survivors only existed in the CVVHDF group with the mortality rate of $50 \%$, in contrast, in the HD/PD group with that of $100 \%(p=0.029)$. Conclusions: Although CVVHDF was applied to the more severe patients, there was no significant difference of mortality rate between the two groups. Considering that, CVVHDF might give a survival benefit 
to the severe cases with the APACHE III score over 90, especially. Therefore, CVVHDF could be more useful method than HD/PD as an initial RRT for the patients with renal failure after major cardiovascular surgery.

\section{8 \\ Effect of Dose and Modality in Pediatric CRRT: A Report of the Prospective Pediatric Continuous Renal Replacement Therapy (ppCRRT) Registry Group}

J.M. Symons, M.J.G. Somers, M. Baum, P.D. Brophy,

J. Fortenberry, D. Blowey, J. Mahan, F.X. Flores,

T.E. Bunchman, R. Hackbarth, A.N. Chua,

S.R. Alexander, S.L. Goldstein

ppCRRT Registry Group, Houston, Texas, USA

There is little evidence to guide CRRT prescription in children. Modality is often based on provider preference; dose is often chosen by convention. We report results from the ppCRRT Registry comparing modalities and level of delivered dose in pediatric CRRT. 100/160 Registry patients received CRRT using only one modality (CVVH, CVVHD or CVVHDF). There was no statistically significant difference in survival between modalities. Delivered dose of CRRT, defined as the sum of all effluent (dialysate plus gross ultrafiltrate) per hour normalized for body surface area, was evaluated for $93 / 100$ subjects. Median dose was $1,888 \mathrm{ml} / \mathrm{h} / 1.73 \mathrm{~m}^{2}$ (range $241-12,712 \mathrm{ml} / \mathrm{h} /$ $1.73 \mathrm{~m}^{2}$ ). There was no statistically significant difference in survival between higher doses of clearance and lower doses $(>$ or $<2,000 \mathrm{ml} / \mathrm{h} /$ $1.73 \mathrm{~m}^{2}$ ). No single modality is clearly superior for pediatric CRRT. Delivered dose of CRRT does not seem to have a strong impact on survival in our Registry. Both findings suggest other factors are principal determinants of outcome in pediatric CRRT.

\begin{tabular}{|c|c|c|c|c|c|}
\hline & $\mathrm{N}$ & Survivors & $\begin{array}{l}\text { Non- } \\
\text { survivors }\end{array}$ & $\begin{array}{l}\text { Survival } \\
\%\end{array}$ & $\mathrm{P}$ \\
\hline \multicolumn{6}{|l|}{ Modality } \\
\hline $\mathrm{CVVH}$ & 33 & 23 & 10 & 0.70 & \\
\hline CVVHD & 61 & 31 & 30 & 0.51 & 0.193 \\
\hline CVVHDF & 6 & 4 & 2 & 0.67 & \\
\hline \multicolumn{6}{|l|}{ Delivered dose } \\
\hline $\begin{array}{l}\text { High dose } \\
\left(>2,000 \mathrm{ml} / \mathrm{h} / 1.73 \mathrm{~m}^{2}\right)\end{array}$ & 43 & 24 & 19 & 0.60 & 0.687 \\
\hline $\begin{array}{l}\text { Low dose } \\
\left(<2,000 \mathrm{ml} / \mathrm{h} / 1.73 \mathrm{~m}^{2}\right)\end{array}$ & 50 & 30 & 20 & 0.56 & \\
\hline
\end{tabular}

The 9th International Conference on

Continuous Renal Replacement

Therapies (CRRT)

\section{9 \\ Demographic Characteristics of Pediatric CRRT: A Report of the Prospective Pediatric Continuous Renal Replacement Therapy (ppCRRT) Registry Group}
A.N. Chua, S.R. Alexander, S.L. Goldstein, M.J.G. Somers, M. Baum, T.E. Bunchman,
R. Hackbarth, P.D. Brophy, J. Fortenberry,
D. Blowey, J. Mahan, F.X. Flores, J.M. Symons
ppCRRT Registry Group, Houston, Texas, USA

We report demographic characteristics and outcome for the first 140 consecutive children with complete data enrolled in the ppCRRT Registry since $1 / 1 / 01$. Ages were newborn to 25 years, $61 \%$ males, weights $1.3-118 \mathrm{~kg}$ (median $25 \mathrm{~kg}$ ). Subjects averaged 6.6 days in ICU prior to CRRT (range 0-103, median 2). At CRRT initiation, $39 \%$ were on diuretics and $64 \%$ were on vasoactive drugs. The table lists indications for CRRT and primary diagnoses. 29\% received CVVH alone; $60 \%$ received CVVHD alone; others received multiple modalities. Median blood flow $\left(\mathrm{Q}_{\mathrm{B}}\right)$ was $100 \mathrm{ml} / \mathrm{min}$ (range $15-350 \mathrm{ml} / \mathrm{min}$ ); median $\mathrm{Q}_{\mathrm{B}}$ per body weight was $3.9 \mathrm{ml} / \mathrm{min} / \mathrm{kg}$ (range $1.1-40 \mathrm{ml} / \mathrm{min} / \mathrm{kg}$ ). Days on CRRT were $<1-99$ (median 6). Overall survival was $56 \%$. There were no survivors past 21 days of CRRT. Survivors and non-survivors were not significantly different for other reported demographic data. We conclude that (1) CRRT can be used successfully for a wide range of critically ill pediatric patients and (2) that patient survival is best for patients without multiple organ involvement. We speculate that earlier use of CRRT to prevent fluid overload may lead to better outcomes and sicker patients with selected diagnoses may have lower survival.

\begin{tabular}{|c|c|c|c|c|}
\hline & $\mathrm{N}$ & Survivors & $\begin{array}{l}\text { Non- } \\
\text { survivors }\end{array}$ & $\begin{array}{l}\text { Survival } \\
\%\end{array}$ \\
\hline \multicolumn{5}{|l|}{ Indications for CRRT } \\
\hline $\begin{array}{l}\text { Fluid overload and } \\
\text { electrolyte imbalance }\end{array}$ & 60 & 29 & 31 & 48 \\
\hline Fluid overload only & 41 & 25 & 16 & 61 \\
\hline $\begin{array}{l}\text { Electrolyte imbalance } \\
\text { only }\end{array}$ & 19 & 11 & 8 & 58 \\
\hline $\begin{array}{l}\text { Prevent fluid overload } \\
\text { to allow intake }\end{array}$ & 8 & 6 & 2 & 75 \\
\hline Other & 12 & 8 & 4 & 67 \\
\hline \multicolumn{5}{|l|}{ Diagnoses } \\
\hline Sepsis & 40 & 22 & 18 & 55 \\
\hline $\begin{array}{l}\text { Cardiac disease/ } \\
\text { transplant }\end{array}$ & 20 & 12 & 8 & 60 \\
\hline $\begin{array}{l}\text { Bone marrow } \\
\text { transplant }\end{array}$ & 15 & 3 & 15 & 20 \\
\hline Renal failure & 15 & 10 & 5 & 67 \\
\hline Malignancy & 12 & 6 & 6 & 50 \\
\hline Pulmonary failure & 8 & 7 & 1 & 87.5 \\
\hline $\begin{array}{l}\text { Inborn error of } \\
\text { metabolism }\end{array}$ & 7 & 5 & 2 & 71 \\
\hline $\begin{array}{l}\text { Liver disease/ } \\
\text { transplant }\end{array}$ & 6 & 3 & 3 & 50 \\
\hline Hypovolemic shock & 4 & 3 & 1 & 75 \\
\hline Drug toxicity & 3 & 3 & 0 & 100 \\
\hline Other & 10 & 5 & 5 & 50 \\
\hline
\end{tabular}




\section{Emerging Concepts in ARF and CRRT}

\section{0 \\ Clinical Evaluation of Direct Hemoperfusion Using a Polymyxin B Immobilized Column (PMX-DHP) in ARDS Patients with Sepsis}

\author{
Y. Kuroki, T. Ikeda, K. Ikeda, M. Nagura, \\ M. Matsushita, J. Taniuchi \\ Hachioji Medical Center, Tokyo Medical University, \\ Tokyo, Japan
}

Objectives: Acute respiratory distress syndrome (ARDS) is characterized by a high mortality rate in patients with sepsis. The purpose of this study is to verify whether direct hemoperfusion using a polymyxin B immobilized column (PMX-DHP) improves the lung oxygenation in ARDS associated with sepsis. Methods: Seventy patients with sepsis whose $\mathrm{PaO}_{2} / \mathrm{FiO}_{2}(\mathrm{P} / \mathrm{F})$ ratio was below 200 were enrolled in this study. PMX-DHP was carried out for $2 \mathrm{~h}$. Mean arterial pressure (MAP), P/F ratio and humoral mediators (interleukin-6 (IL-6), interleukin-1 receptor antagonist (IL-1 ra), intercellular adhesion molecule-1 (ICAM-1), plasminogen activator inhibitor-1 (PAI-1), interleukin-8 (IL-8), and neutrophil elastase) were measured before and after PMX-DHP. Results: Forty-four of 70 patients $(63 \%)$ survived 28 days after PMX-DHP. P/F ratio increased significantly from $132 \pm 42$ to $159 \pm 76$ torr after PMX-DHP ( $p>0.001)$. MAP increased significantly from $72 \pm 17$ to $84 \pm 16 \mathrm{mmHg}$ after PMXDHP ( $p>0.001)$. IL-6 and IL-1 ra decreased significantly after PMXDHP ( $p=0.04$ and 0.02 , respectively). PAI-1 decreased significantly in the survivors $(p>0.001)$, but did not change significantly in nonsurvivors. ICAM-1, IL-8, and neutrophil elastase showed no significant change after PMX-DHP. Conclusion: PMX-DHP improved hemodynamic state and lung oxygenation in patients with sepsis.

\section{1}

\section{Advanced Monitoring Methods for Filter Clogging Using Fast Fourier Transform Analysis of Pressure Waves}

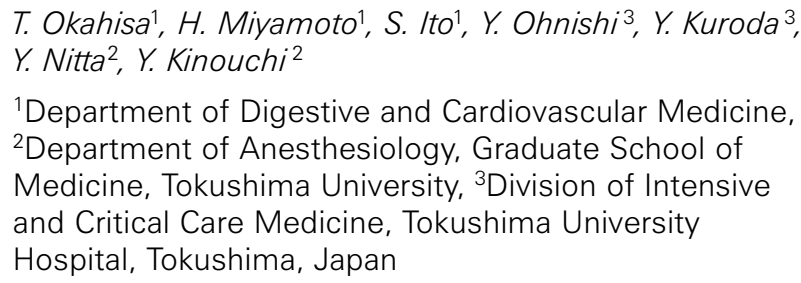

Purpose: In order to perform continuous renal replacement therapy safely, it is desirable to discover filter clogging at an early stage, adjust the amount of anticoagulant appropriately and adjust its flow rate to prevent further clogging. In this study, we assessed filter clogging monitoring methods using Fast Fourier Transform (FFT) analysis of the pressure wave created by blood pumping. Methods: Hemofiltrations using several degrees clogged hemofilter were performed in an in vitro tank model. Pressure in the bubble trap chamber of the pre filter $(\mathrm{Pa})$, post filter $(\mathrm{Pv})$, and in the drainage tube of waste fluid (Pf) were measured by a pressure monitoring system at a sampling frequency of $100 \mathrm{~Hz}$. The power and the phase of the basal frequency of the blood roller pump pressure wave were obtained using FFT. The power ratios $[\mathrm{G}(\mathrm{w}) \mathrm{f} / \mathrm{a}$ and $\mathrm{G}(\mathrm{w}) \mathrm{v} / \mathrm{a}]$ and the phase differences $[\angle \mathrm{G}(\mathrm{w})$ f/a and $\angle G(w)$ v/a] were calculated. Results: As the filter clogging increased, the $\mathrm{G}(\mathrm{w}) \mathrm{f} / \mathrm{a}$ decreased and the phase differences increased. The $G(w)$ v/a showed an increase in the initial stages of filter clogging followed by a decrease as the filter clogging became more severe. The power ratios changed greatly in comparison with the pressure indexes. Conclusion: The above results indicate that it may be possible to monitor filter clogging at an early stage by continuously analyzing the conductive condition of the roller pump flow pressure wave using FFT.

\section{2 \\ Pharmacy Errors and Patient Complications in CRRT: Survey Results from Listserves}

\author{
T.E. Bunchman 1 , J.J. Gardner ${ }^{1}$, N.J. Maxvold ${ }^{2}$ \\ A.Z. Koch ${ }^{3}$, D.M. Eding ${ }^{2}$, R.M. Hackbarth ${ }^{2}$ \\ ${ }^{1}$ Nephrology, ${ }^{2}$ Critical Care, ${ }^{3}$ Pharmacy, \\ DeVos Children's Hospital, Michigan, USA
}

Continuous renal replacement therapy (CRRT) solutions have been extemporaneous pharmacy or Industry solution. No literature is available on the errors or complications from extemporaneous pharmacy solution, yet programs (prgs) have noted complications and formulated policies to prevent future errors. Listserves for Pediatric CRRT, Pediatric Critical Care and Pediatric Nephrology were confidentially queried on Pediatric CRRT (PCRRT) management and complications related to PCRRT solutions and anticoagulation. Thirty-one prgs responded (patient volume of 2-41 PCRRT patients/year). Modalities were CVVH (9 prgs), CVVHD (7 prgs), CVVHDF (7 prgs) and varying CRRT modalities (8 prgs). Anticoagulation was heparin (20 prgs) or citrate (11 prgs). Solution used for Replacement (CVVH or CVVHDF) were extemporaneous pharmacy solution (14 prgs), Normocarb (NC; 2 prgs) and Normal Saline/Lactated Ringers (4 prgs). Solution used for Dialysate were extemporaneous pharmacy solution (13 prgs), NC (2 prgs), Prismasate (P; 2 prgs), Hemofiltration Solution (3 prgs). Eighteen of 31 prgs (58\%) have noted at least one error with extemporaneous pharmacy solution (16 prgs; 7 replacement solution, 9 dialysate solution) or anticoagulation ( $2 \mathrm{prgs})$. Sixteen solution errors resulted in 2 deaths, 1 cardiac arrest with survival, 6 seizures (hypo/hypernatremia) and 7 patients without complications. Two children had bleeding due to heparin concentration errors. Policy changes included at least one of the following: change to $\mathrm{NC}$ for replacement or dialysate solution (11 prgs), change to $\mathrm{P}$ for dialysate solution ( 2 prgs), TPN compounder for extemporaneous pharmacy PCRRT solution production ( $2 \mathrm{prgs})$, lab checking of each extemporaneous pharmacy bag ( 3 prgs) and label check by 2 nursing staff (10 prgs). In conclusion, lethal and near lethal events from errors in extemporaneous pharmacy solutions occur. Complications in the setting of dealing with critically ill children (or possibly in adults) may be unrecognized 
and are underreported. Given the option to use safe Industry solutions which may reduce the risk of lethal or near lethal complications, extemporaneous pharmacy solutions have no place in PCRRT.

13

\section{The Double-Bag Type Bicarbonate Substitution Fluid Set (Sublood-BD) can Reduce Preparation Time and the Amount of Contaminated Foreign Matter Introduced}

\section{T. Okahisa 1, I. Hiroshi ${ }^{1}$, I. Susumu', O. Yoshiaki²,}

K. Yasuhiro², T. Masahiro ${ }^{3}$

${ }^{1}$ Department of Digestive and Cardiovascular Medicine, Graduate School of Medicine, ${ }^{2}$ Division of Intensive and Critical Care Medicine, Tokushima University Hospital, Tokushima, ${ }^{3}$ Research and Development Department, Fuso Pharmaceutical Industries LTD., Osaka, Japan

Purpose: Bicarbonate substitution fluid for continuous renal replacement therapy (CRRT) requires mixing two solutions before use. This process is complicated and time-consuming, causing problems such as mixing an incorrect solution or contamination with bacteria and/or foreign matter. In order to resolve these problems, we developed a double-bag type bicarbonate substitution fluid set (Sublood-BD, Fuso Pharmaceutical Industries LTD., Japan). In this study, we assessed its' preparation time and the level of the contaminated foreign matter. Method: We compared the preparation times of 14 medical staff using the Sublood-BD and using the conventional bicarbonate substitution fluid set (Sublood-BD, Fuso Pharmaceutical Industries LTD., Japan). We examined the contaminated foreign matter in the mixed fluid and other, double-bag type, intravenous fluid sets using microscopic particle count test. We also examined the septic wall exfoliation side using an electron-microscope. Results: The preparation time of the Sublood-BD was $2 / 3$ of the time required for the conventional set. Sublood-BD made it possible to mix the solutions with significantly lower levels of contamination than others. Conclusions: Since the Sublood-BD septic wall is made of polyethylene only, its septic wall exfoliation side is smoother in comparison with other, double-bag type, intravenous fluid sets, which are made of polyethylene and polypropylene. Sublood ${ }^{\circledR}$-BD reduces preparation time and contamination and increases working efficiency and safety.

\section{4 \\ Identification of Early Biomarkers of Tubular Injury: The Role of Urinary Sodium Excretion and Protein Fragmentation}

\author{
V. Cantaluppi, A. Pacitti, C.M. Fenocchio, G. Podda, \\ G. Lanfranco, G.P. Segoloni
}

Nephrology, Dialysis and Renal Transplantation Unit, San Giovanni Battista Molinette Hospital, Torino, Italy

Injury of tubular cells is a key event in Acute Renal Failure (ARF). The mechanisms of tubular damage have been clarified: first, a sub-lethal injury occurs with loss of polarity, modification of sodium excretion and detachment of viable cells from basal membrane with consequent fall in the lumen and obstruction of urine flow. The severity of ischemic or toxic insults determines the fate of the cells in the direction of necrosis/apoptosis or of recovery of epithelial integrity. Even though the alterations of urinary output and of blood creatinine levels are the standardized parameters to diagnose ARF even in more recent criteria such as RIFLE, the finding of early markers of tubular injury in urine may help to identify patients at high risk of development of Acute Tubular Necrosis (ATN), allowing appropriate therapeutic strategies. In the last years (2001-2003) we followed in 10 different ICUs 523 patients affected by ARF, most of them requiring Renal Replacement Therapy (RRT). In the presence of oliguria, spot urine sodium value $(\mathrm{uNa})$ was a specific indicator of ATN $(>20 \mathrm{mEq} / \mathrm{L})$ or of 'pre-renal' conditions $(<20 \mathrm{mEq} / \mathrm{L})$ including hepato-renal syndrome and congestive heart failure. In the last months, we started to make urinary examination to all patients admitted to ICUs: in 10 cases we found digested urine proteins on electrophoresis examination. ARF was mostly due to ATN for ischemia after heart surgical procedures or coronary artery disease, only 4 patients had a certain diagnosis of sepsis, all urine bacteriologic cultures were negative, 9/10 necessitated RRT and $40 \%$ had a full recovery of renal function (Table). Our hypothesis is that proteases released from infiltrating leukocytes or activated 'in situ' on tubular

\begin{tabular}{|c|c|c|c|c|c|c|c|}
\hline Patients & Sex & Age & Etiology of ARF & $\begin{array}{l}\text { Basal } \\
\mathrm{Cr}\end{array}$ & $\begin{array}{l}\text { Peak } \\
\mathrm{Cr}\end{array}$ & $\begin{array}{l}\text { Need } \\
\text { of RRT }\end{array}$ & $\begin{array}{l}\text { Recovery } \\
\text { of renal } \\
\text { function }\end{array}$ \\
\hline 1 & M & 56 & $\begin{array}{l}\text { Toxic: ATN in } \\
\text { myeloid leukemia }\end{array}$ & 1.4 & 6.2 & Yes & No \\
\hline 2 & M & 73 & $\begin{array}{l}\text { Ischemia: ATN } \\
\text { in heart surgery } \\
\text { (aortic stenosis and } \\
\text { aorto-coronary } \\
\text { by-pass) + sepsis }\end{array}$ & 1.1 & 3.6 & Yes & No \\
\hline 3 & M & 76 & $\begin{array}{l}\text { Ischemia: ATN } \\
\text { in heart surgery } \\
\text { (aorto-coronary } \\
\text { by-pass) }\end{array}$ & 1.2 & 4.6 & Yes & Yes \\
\hline 4 & M & 73 & $\begin{array}{l}\text { Ischemia: ATN } \\
\text { in heart surgery } \\
\text { (aorto-coronary } \\
\text { by-pass) + sepsis }\end{array}$ & 1.1 & 4.8 & Yes & Yes \\
\hline 5 & M & 53 & $\begin{array}{l}\text { Ischemia: ATN } \\
\text { in heart surgery } \\
\text { (aortic dissection) }\end{array}$ & 0.9 & 5.1 & Yes & Yes \\
\hline 6 & M & 78 & $\begin{array}{l}\text { Ischemia: ATN in } \\
\text { myocardial infarction }\end{array}$ & 1.0 & 3.1 & Yes & Yes \\
\hline 7 & M & 70 & $\begin{array}{l}\text { Ischemia: ATN in } \\
\text { myocardial infarction }\end{array}$ & 1.0 & 4.6 & No & Yes \\
\hline 8 & M & 68 & $\begin{array}{l}\text { Ischemia: ATN after } \\
\text { thoracic surgery } \\
\text { (lung neoplasm) }\end{array}$ & 1.2 & 3.0 & Yes & Yes \\
\hline 9 & $\mathrm{~F}$ & 79 & $\begin{array}{l}\text { Ischemia: ATN } \\
\text { in heart surgery } \\
\text { (aorto-coronary } \\
\text { by-pass) + sepsis }\end{array}$ & 2.9 & 2.9 & Yes & No \\
\hline 10 & $\mathrm{~F}$ & 69 & $\begin{array}{l}\text { Ischemia: ATN } \\
\text { in hepato-renal } \\
\text { syndrome }+ \text { sepsis }\end{array}$ & 2.2 & 6.2 & Yes & Yes \\
\hline
\end{tabular}


cells may generate a pro-inflammatory microenvironment still concomitant to low uNa values. As a following step, the balance between toxic and protective agents leads to ATN (presence of complete tubular proteinuria) or to recovery of renal function. Thus, the presence of fragmented protein in urine may be an early indicator of sub-lethal tubular 'stress'. Further investigations on biopsy proven ARF and comparison with other markers of tubular injury are required.

15

\section{Prediction of Vancomycin Plasmatic Levels during Sustained Slow Hemofiltration (SHF) through the Application of a Steady-State Continuous Infusion Model}

\section{A. Pacitti ${ }^{1}$, V. Cantaluppi ${ }^{1}$, C.M. Fenocchio ${ }^{1}$, V. Veglio ${ }^{4}$, D. Moscato ${ }^{2}$, M. Vaj ${ }^{3}$ \\ ${ }^{1}$ Nephrology, Dialysis and Renal Transplantation Unit, ${ }^{2}$ Baldi e Riberi Laboratory, ${ }^{3}$ Intensive Care Unit, San Giovanni Battista Molinette Hospital, ${ }^{4}$ Infective Disease Unit, Amedeo di Savoia Hospital, Torino, Italy}

Vancomycin (VA), removed by kidneys and by convective renal replacement therapies (RRT) with a Sieving Coefficient (VA_SC) of 0.7 should maintain adequate and stable plasmatic levels (VA_p) to exert full activity avoiding side-effects. Because intermittent VA therapy must cope with patient distribution volume, we propose a steadystate model (SSM) independent from body weight. After a loading intermittent dose (LD) of $15 \mathrm{mg} / \mathrm{kg}$ in $12 \mathrm{~h}$, a continuous infusion is modulated in relation to residual $(\mathrm{ResCl})$ and artificial clearance ( $\mathrm{ArtCl})$, pointing to a Target Concentration (TAC) in equilibrium between drug supply and elimination: VA Dose $(\mathrm{DA})=(\mathrm{ResCl}+$ ArtCl) $\times$ TAC $\times$ VA_SC. The study aim was to test the SSM in patients submitted to RRT for maintaining a $20 \mathrm{mg} / \mathrm{ml}$ TAC. Ten septic ARF patients ( 9 anuric) were treated in ICU. SHF was run daily for periods of $12 \mathrm{~h}, \mathrm{qB}=200 \mathrm{ml} / \mathrm{min}$, effluent rate $=50 \mathrm{ml} / \mathrm{min}$, a maximal ultrafiltration (UF) rate $=350 \mathrm{ml} / \mathrm{h}$, prediluition = $30-40 \mathrm{ml} / \mathrm{min}$ and urea clearance of about $45 \mathrm{ml} / \mathrm{min}$. Plasma and UF samples were collected pre-post SHF to calculate VA_p and VA_SC. After the LD, during SHF the DA was increased from basal periods without on-going SHF treatment (DA_BAS = empirically found of $250 \mathrm{mg} / 24 \mathrm{~h}$ resulting from a $\mathrm{ResCL}=8.5 \mathrm{ml} / \mathrm{min}$ ) to DA_SHF measured according to the SSM. VA_p reached the prefixed TAC $(20 \mathrm{mg} / \mathrm{ml})$ with average VA_p of $22.4 \pm 5.1 \mathrm{mg} / \mathrm{ml}(\mathrm{N}=117, \mathrm{SE}=$ 0.47 ), independently from the starting level pointing to a steady state after few SHF hours: in fact VA_p showed less dispersion during SHF period, (DS $= \pm 3.4$ ). By contrast, VA_p $<25 \%$ from TAC were $3.4 \%$. VA_SC was $0.7 \pm 0.1$. In conclusion, the application of SSM based on clearances derived from RRT allowed stable VA_p, avoiding the intermittent dosage mode with peak levels and speculations on distribution volume. Every drug active at trough levels and eliminated by renal route could be handled safer and with lower monitoring costs by SSM in ICU patients submitted to RRT.
16

\section{Development of an in vitro Model of Continuous Renal Replacement Therapy (CRRT) Solute Removal}

\author{
D.A. Pasko ${ }^{1,2}$, M.D. Churchwell ${ }^{1}$, B.A. Mueller ${ }^{1,3}$ \\ ${ }^{1}$ Department of Clinical Sciences, University of Michigan \\ College of Pharmacy, ${ }^{2}$ CS Mott Children's Hospital, \\ ${ }^{3}$ Department of Pharmacy Services, University Hospital, \\ Michigan, USA
}

Background: CRRT solute clearance is mainly a function of blood flow, dialysate rate or ultrafiltration rate, solute molecular weight, solute protein binding, CRRT mode, and filter type. These factors are interdependent and to determine this interrelationship within a given patient is difficult with many confounding patientspecific variables. Purpose: We developed a CRRT model to determine solute clearance during CRRT that allows us to independently alter filters, modes, rates, dialysate content to assess solute clearance during CRRT. Methods: We developed an in vitro bovine-blood based CRRT system using custom-made dialysate solution (for CVVHD) on a B. Braun Diapact ${ }^{\mathbb{R}}$ machine using Diapact ${ }^{\mathrm{TM}}$ CRRT kit tubing. One liter of bovine whole blood was anticoagulated with $3.8 \%$ sodium citrate continuously stirred in a glass flask submerged in a $37^{\circ} \mathrm{C}$ water bath. Dextrose and investigational solutes are added to the bovine blood. In continuous veno-venous hemofiltration (CVVH) mode, we recirculate ultrafiltrate back into blood to maintain constant hematocrit and no overall solute loss. CVVHD blood can be run in single pass or recirculating mode. Blood can be sampled pre-filter and post filter. Dialysate and ultrafiltrate can be sampled from the spent dialysate/formed ultrafiltrate port. Results: We have used this CRRT model to operate continuously for up to $72 \mathrm{~h}$ without complication. Sieving coefficient, saturation coefficient, and solute clearance data derived from this model have been consistent and reproducible through a variety of experimental CVVH and CVVHD parameters. Conclusion: This model is useful in determining solute clearance by CRRT but in vivo studies should be done to determine whether our findings can be replicated in patients treated with CRRT.

\section{7}

\section{Keys for a Successful CRRT Educational Program}

J. Willis' ${ }^{1}$, K.S. Hodge', J. Dwyer ${ }^{2}$

${ }^{1}$ Clarian Health Partners - IU Campus, ${ }^{2}$ Clarian Health

Partners - Methodist Campus, Indianapolis, Indiana, USA

Purpose: Variations in CRRT nursing practice were observed both within and between critical care units. The goal was to redesign the education program to assure reliable and consistent CRRT nursing practice, patient care, and desired patient outcomes. Methods: An eight-hour CRRT Class for the novice practitioner occurs bi-monthly, and includes both cognitive and psychomotor activities. Multidisciplinary presenters are utilized and are considered local experts in the field of CRRT. Equipment skill validation stations are conducted using identified critical elements. A documentation exercise is 
required to assure documentation standards and accurate CRRT flowsheet utilization. Cognitive validation occurs via a pre/post-test methodology. Instititutional policy, physician order set, troubleshooting guidelines and other valuable resource materials are distributed in a course manual. Attendees transition from the classroom into clinical practice using a Preceptor Model and CRRT orientation checklist. To fully actualize the goal for reliable, consistent, 'best practice' CRRT nursing management on an ongoing basis, critical care and dialysis nurses participate in an annual CRRT competency process. Skill stations use the critical element approach. Maintained knowledge is validated with a paper assessment tool. Recently, an Advanced CRRT Class was added to the CRRT Education Program. This new class provides a forum for facilitated discussion of new therapy updates, management nuances, and group discussion of challenging patient situations. Summary: Participant class evaluations consistently reflect excellent scores for the content, speakers, and overall format of our course. Annual competency activities are valuable to validate knowledge base and nursing practice. The Advanced CRRT Class provides opportunity for facilitated discussion of complex case situations and troubleshooting challenges that are assigned to this group of expert nurses. Outcomes: We have great pride with the evaluation of our Clarian CRRT Education Process and patient management outcomes! Presentation of this program at the Midwest CRRT Symposium generated much enthusiastic discussion and direction for program revisions at other facilities both within Indiana and in surrounding states. It is strongly anticipated that this content will continue to be valuable for participants attending The Ninth International Conference on Continuous Renal Replacement Therapies.

18

\section{Mathematical Modeling of Ultrafiltration}

\author{
N. Hemasilpin', M.M. Polycarpou², J.J. Bissler ${ }^{1,3}$ \\ ${ }^{1}$ Cincinnati Children's Hospital Medical Center, \\ ${ }^{2}$ Department of Electrical and Computer Engineering \\ and Computer Sciences, University of Cincinnati, \\ 3University of Cincinnati College of Medicine, \\ Cincinnati, Ohio, USA
}

Teaching nephrology fellows about hemodialysis and hemofiltration includes instilling a detailed understanding of the cardiovascular response to ultrafiltration. Patient tolerance of ultrafiltration is dependent on the net balance of the lymphatic return and the utlrafiltration rates. The lymphatic system not only supplies the interstitial fluid but also helps control the blood pressure prior to the triggering nervous and the humoral regulation. The lymphatic return contribution to blood pressure control is affected by a property called vascular stressrelaxation. A precise quantitative knowledge of lymphatic return rate and vascular stress-relaxation property is essential for optimizing a physiologically appropriate ultrafiltration rate. To this end, we have designed a method of modeling both the lymphatic return rate and the vascular stress-relaxation property. We have derived a set of dynamical equations to represent the cardiovascular system including capillary dynamics, lymphatic flow, interstitial fluid dynamics, and vascular stress-relaxation property based on physiological data. This set of equations allows the prediction of the blood pressure response during ultrafiltration, and fellows can perform virtual experiments using this 'model patient' to begin to appreciate the different responses to ultrafiltration given different pathological states.

\section{9}

\section{Impact of Vascular Acces Dysfunction on Dialysis Dose in ICU-Acute Renal Failure Patients}

\author{
L. Amigues ${ }^{1}$, K. Klouche1, P. Massanet ${ }^{1}$, S. Deleuze ${ }^{2}$ \\ B. Canaud ${ }^{2}$, J.J. Beraud ${ }^{1}$ \\ ${ }^{1}$ Intensive Care Unit and ${ }^{2}$ Nephrology Department, \\ Lapeyronie University Hospital, Montpellier, France
}

We investigated 43 hemodialysis sessions in order to evaluate the discrepancy between the prescribed $(\mathrm{pKt} / \mathrm{V})$ and the delivered $\mathrm{Kt} / \mathrm{V}$ $(\mathrm{dKt} / \mathrm{V})$ in ICU-acute renal failure and to identify some potential causes. Methods: 10 patients with acute renal failure, APACHE $\mathrm{II}=31.6 \pm 5.6$, were included. Vascular access: femoral vein with two 18 gauge's catheters, dialysis generator: Fresenius $4008 \mathrm{H}$, filter: Nephral 400 ST (Hospal), $1.65 \mathrm{~m}^{2}$ membrane. Dialysate flow rate: $500 \mathrm{ml} / \mathrm{min}$, blood flow rate: $200 \mathrm{ml} / \mathrm{min}$ or $300 \mathrm{ml} / \mathrm{min}$. In case of catheter dysfunction, catheter connexions were reversed (reversed $\mathrm{KT}$ ). Data collected during hemodialysis sessions: $\mathrm{pKt} / \mathrm{V}$ (calculated from the in vitro clearance), $\mathrm{dKt} / \mathrm{V}$ (Daugirdas II), $\% \mathrm{Kt} / \mathrm{V}=$ $(\mathrm{dKt} / \mathrm{V} / \mathrm{pKt} / \mathrm{V}) / 100$, effective blood flow and its percentage $\left(\% \mathrm{Q}_{\mathrm{B}}\right)$ from the prescribed blood flow, systemic anticoagulation, session with reversed KT and hypotension during dialysis. Two groups of hemodialysis session characterized by a $\% \mathrm{Kt} / \mathrm{V}$ above or below 83.4\% were compared regarding all data. Results: All sessions: $\mathrm{pKt} / \mathrm{V}=1.21 \pm 0.22, \mathrm{dKt} / \mathrm{V}=1.01 \pm 0.21$ and $\% \mathrm{Kt} / \mathrm{V}=84.8 \pm$ $15.3 \%$.

\begin{tabular}{llll}
\hline & $\% \mathrm{Kt} / \mathrm{V}>83.4 \%$ & $\% \mathrm{Kt} / \mathrm{V}<83.4 \%$ & $\mathrm{P}$ \\
\hline Number of sessions & 21 & 22 & \\
$\% \mathrm{Kt} / \mathrm{V}$ & $97.3 \pm 8.1$ & $72.9 \pm 10.2$ & $\mathrm{P}<0.05$ \\
$\% \mathrm{Q}_{\mathrm{B}}$ & $100.4 \pm 3.8$ & $97.5 \pm 4.9$ & $\mathrm{P}<0.05$ \\
Reversed KT & $0 / 21$ & $9 / 22$ & $\mathrm{P}<0.05$ \\
Anticoagulation & $13 / 21$ & $13 / 22$ & $\mathrm{NS}$ \\
Hypotension & $0 / 21$ & $3 / 22$ & $\mathrm{P}<0.05$ \\
\hline
\end{tabular}

Conclusions: Delivered $\mathrm{Kt} / \mathrm{V}$ in ICU-acute renal failure represents $84.8 \%$ of the prescribed $\mathrm{Kt} / \mathrm{V}$. The influential factor identified in this study was the catheter dysfunction. 
Technique Characteristics

20

\section{Application of Continuous Renal Replacement Therapy in Patients with Combined Liver-Kidney Transplantation}

\author{
M. Zhang ${ }^{1}$, Y.-T. Ding ${ }^{2}$ \\ ${ }^{1}$ Renal Division, ${ }^{2}$ Department of Surgery, \\ Affiliated Gulou Hospital of Nanjing University, \\ Nanjing, P.R. China
}

Objective: To evaluate the applicating valve of continuous renal replacement therapy (CRRT) in patients with combined liver-kidney transplantation (CLKT). Methods: Five chronic liver and kidney failure patients were enrolled in this study, including 3 males and 2 females with an average age of $48.2 \pm 6.7$ years. All of the 5 patients had a child-c preoperative hepatic function and the creatinine clearance of the patients were less than $6 \mathrm{~mL} / \mathrm{min}$. Three of them existed disturbance of blood coagulation. Liver and kidney transplantation were orthotopic and ordinary methods, respectively. Continuous veno-venous hemofiltration $(\mathrm{CVVH})$ was performed during the operation. We don't use anticoagulants in the patients. The patients were treated by pre-dilution. Results: All of these patients vital signs and hemodynamics were stable during the operation. The average treatment hour of CVVH was $14.7 \pm 3.2$. Mean intra-operative transfusion of fresh frozen plasma was $6,000-7,800 \mathrm{~mL}$ and whole blood was $6,000-9,400 \mathrm{~mL}$. The replacement solution was $2-4 \mathrm{~L} / \mathrm{h}$. Change of clinical characteristics in the patients showed that the vital signs trend to be more stable. All patients were maintained in a steady state of blood pressure and heart rate during CVVH. Electrolyte and blood gas analysis ameliorated obviously after CRRT $(\mathrm{p}<0.05)$. Both transplant organs had rapidly normal functions postoperation. No clot was found in the filter. Conclusions: CRRT is good for maintaining the balance of electrolytes and hemodynamics, and it's an effective therapeutic option for CLKT. CRRT can pull the water from intracellular into the blood continuously, so it can reduce the interference on the stability of cardiovascular system and effectively correct the pathogenic distribution of body fluid quickly and ameliorate tissue edema. The function of vital organs were stable and much of graft function were normal following CRRT. CRRT is an important method of renal and other vital organ support in transplantation, and it can favorably influence prognosis.

\begin{tabular}{lcccc}
\hline & $\begin{array}{l}\text { Before } \\
\text { operation }\end{array}$ & $\begin{array}{l}\text { After } \\
\text { hepatectomy }\end{array}$ & $\begin{array}{l}\text { Before kidney } \\
\text { transplantation }\end{array}$ & $\begin{array}{l}\text { After } \\
\text { operation }\end{array}$ \\
\hline $\mathrm{K}^{+}(\mathrm{mmol} / \mathrm{L})$ & $5.3 \pm 0.5$ & $4.8 \pm 0.7^{*}$ & $4.7 \pm 0.6^{*}$ & $3.9 \pm 0.4^{*}$ \\
$\mathrm{Na}^{+}(\mathrm{mmol} / \mathrm{L})$ & $140 \pm 2.9$ & $139 \pm 3.2$ & $138 \pm 2.8$ & $137 \pm 2.4$ \\
$\mathrm{BUN}(\mathrm{mmol} / \mathrm{L})$ & $32.4 \pm 3.4$ & $31.7 \pm 4.9$ & $30.1 \pm 2.5$ & $29.3 \pm 3.2$ \\
$\mathrm{Scr}(\mu \mathrm{mol} / \mathrm{L})$ & $620.3 \pm 3.3$ & $600.5 \pm 3.7^{*}$ & $574.6 \pm 2.9^{*}$ & $561.4 \pm 4.8^{*}$ \\
$\mathrm{HCO}(\mathrm{mmol} / \mathrm{L})$ & $16.6 \pm 4.3$ & $17.3 \pm 2.6^{*}$ & $18.2 \pm 3.5^{*}$ & $19.4 \pm 3.9^{*}$ \\
$\mathrm{pH}$ vs before & $7.33 \pm 0.19$ & $7.35 \pm 0.15$ & $7.39 \pm 0.13^{*}$ & $7.41 \pm 0.18^{*}$ \\
operation & & & & \\
\hline
\end{tabular}

$* \mathrm{p}<0.05$.
21

\section{Protein Losses in Continuous Renal Replacement Therapies}

F. Ruzany, R.A.N. Paiva, C. Valente, J.H. Suassuna, E. Rocha, E. Maccarielo, M.G. Rodrigues

Barra D'or Hospital and University of State of Rio de Janeiro, Rio de Janeiro, Brazil

Introduction: Continuous renal replacement therapies (CRRT) readily allow for the nutritional support of these high catabolic states, but also contribute to the nitrogen loss through filtration of free amino acids and small peptides across the hemofilters. Amino acids clearances and calculated losses in adults on continuous veno-venous hemodialysis (CVVHD) have been reported in the range of $2-11 \%$ of dietary intake. Objective: To analyse protein losses from CRRT treatments in critical ill patients. Materials and Methods: Paired samples from serum, venous and dialysate/ultrafiltrate were obtained during CRRT procedures from 41 patients in a 27 beds of intensive care unit from July 2002 to May 2003. Paired samples were collected from 1, 6, 12, 24, 36 and $48 \mathrm{~h}$ of continuous hemodialysis, total of six samples of serum, venous and dialysate. PAN 650 filters were used in all patients. Blood flow was $150 \mathrm{ml} / \mathrm{min}$ in all patients and the dialysate flow during CVVHD was $16.6 \mathrm{ml} / \mathrm{min}$. Five patients received no diet. Four patients received oligomeric diet, one patient hyperalimentation intravenous, and the others received polymeric diets. The protein given was $1.3-1.7 \mathrm{~g} / \mathrm{kg}$. Total calorie was $22-25 \mathrm{Kcal} / \mathrm{kg}$. Amino acids assay, by using high-pressure liquid chromatography (HPLC)-serum, venous and dialysate were performed by laboratory CTN and Pardini. Results: Patient age average was 73.08 (43 to 88 years) years and APACHE II score was 18.37 (11 to 28). Serum, venous and dialysate amino acids were obtained in 41 patients and analysed 23 amino acids ( $\mu \mathrm{Mol} / \mathrm{l})$ : Aspartic acid, Glutamic acid, Alanine, Arginine, Asparagine, Cystine, Phenylalanine, Glycine, Glutamine, Hydroxyproline, Histidine, Isoleucine, Leucine, Lysine, Methionine, Ornithine, Proline, Serine, Taurine, Tyrosine, Threonine, Tryptophan, Valine. Analysis were done by average of amino acids. Statistical calculations were by analysis of variance, linear, non-linear and logarithmic regression. Conclusions: The losses of amino acids are more evident with amino acids that are more elevated in the plasma, as: glutamine, alanine, glycine, glutamic acid. It seems that dialysis do not modify the behavior of plasma amino acids.

\begin{tabular}{lllll}
\hline Time & $\begin{array}{l}\text { Serum alanine } \\
(\mathrm{mMol} / \mathrm{l})\end{array}$ & $\begin{array}{l}\text { Serum glutamine } \\
(\mathrm{mMol} / \mathrm{l})\end{array}$ & $\begin{array}{l}\text { Losses alanine } \\
(\mathrm{mMol} / \mathrm{min})\end{array}$ & $\begin{array}{l}\text { Losses glutamine } \\
(\mathrm{mMol} / \mathrm{min})\end{array}$ \\
\hline $1 \mathrm{~h}$ & 878.87 & 675.03 & $1,368.649$ & 1,570 \\
$6 \mathrm{~h}$ & 767.355 & 521.387 & $2,000.669$ & $2,053.711$ \\
$12 \mathrm{~h}$ & 842.05 & 587.9 & $1,857.09$ & $1,032.207$ \\
$24 \mathrm{~h}$ & 854.81 & 408.34 & $3,787.315$ & $2,706.815$ \\
$36 \mathrm{~h}$ & 824.71 & 458.16 & $2,629.606$ & $1,457.058$ \\
$48 \mathrm{~h}$ & 680.85 & 700.3 & $2,410.245$ & $2,469.771$ \\
\hline
\end{tabular}

\begin{tabular}{llll}
\hline tempo & $\begin{array}{l}\text { soma da } \\
\text { perda em } 24 \mathrm{~h}\end{array}$ & $\begin{array}{l}\text { soma das } \\
\text { perdas } \mathrm{mmol} / \mathrm{min}\end{array}$ & $\begin{array}{l}\text { transf.em } \\
\text { gramas/dia }\end{array}$ \\
\hline 6 & $66,017.016$ & 66.017016 & 9.064136 \\
12 & $52,019.7264$ & 52.0197264 & 7.142308 \\
24 & $52,298.9424$ & 52.2989424 & 7.180645 \\
36 & $48,097.8576$ & 48.0978576 & 6.603836 \\
48 & $49,495.2912$ & 49.4952912 & 6.795703 \\
\hline
\end{tabular}




\section{2}

\section{Amino Acids Adherence in Continuous Renal Replacement Therapies}

\author{
F. Ruzany, R.A.N. Paiva, C. Valente, J.H. Suassuna, \\ E. Rocha, E. Maccarielo, M.G. Rodrigues
}

Barra D'or Hospital and University of State of Rio de Janeiro, Rio de Janeiro, Brazil

Introduction: Continuous renal replacement therapies (CRRT) readily allow for the nutritional support of these high catabolic states, but also contribute to the nitrogen loss through filtration of free amino acids and small peptides across the hemofilters, and possible adherence of amino acids. Objective: Evaluate amino acids adherence in CRRT. Materials and Methods: Paired samples from serum, venous and dialysate/ultrafiltrate were obtained during CRRT procedures from 41 patients in a 27 beds of intensive care unit from July 2002 to May 2003. Paired samples were collected from 1, 6, 12, 24, 36 and $48 \mathrm{~h}$ of continuous hemodialysis, total of six samples of serum, venous and dialysate. PAN 650 filters were used in all patients. Blood flows was $150 \mathrm{ml} / \mathrm{min}$ in all patients and the dialysate flow during CVVHD was $16.6 \mathrm{ml} / \mathrm{min}$. Amino acids assay, by using high-pressure liquid chromatography (HPLC)-serum, venous and dialysate were performed by laboratory CTN and Pardini. Adherence was calculated as: Clearance hemodialysis $(\mathrm{CH}) /$ Serum clearance $(\mathrm{SC}) ; \mathrm{CH}=(16.6 \times$ dialysis)/serum amino acids; $\mathrm{SC}=150 \times($ serum amino acids venous amino acids)/dialysis amino acids. Results: Patient age average was 73.08 (43 to 88 years) years and APACHE II score was 18.37 (11 to 28 ). Serum, venous and dialysate amino acids were obtained in 41 patients and analysed 23 amino acids ( $\mu \mathrm{Mol} / 1)$ : Aspartic acid, Glutamic acid, Alanine, Arginine, Asparagine, Cystine, Phenylalanine, Glycine, Glutamine, Hydroxyproline, Histidine, Isoleucine, Leucine, Lysine, Methionine, Ornithine, Proline, Serine, Taurine, Tyrosine, Threonine, Tryptophan, Valine. Analysis were done by average of amino acids. Adherence was not statistically significant, and do not correlate neither with time of hemodialysis nor with serum amino acids. Statistical calculations were by analysis of variance, linear, non-linear and logarithimic regression. Glutamine $\left(\mathrm{R}^{2}=0.978691062\right), \quad$ Alanine $\quad\left(\mathrm{R}^{2}=0.575243703\right)$, Taurine $\left(R^{2}=0.612666425\right)$, Valine $\left(R^{2}=0.743575525\right)$.

\begin{tabular}{lll}
\hline Time & Adherence $24 \mathrm{~h}$ & Adherence $24 \mathrm{~h} / \mathrm{Mmol} / \mathrm{min}$ \\
\hline $1 \mathrm{~h}$ & 0.25898 & 372.9312 \\
$6 \mathrm{~h}$ & 0.376103 & 541.58832 \\
$12 \mathrm{~h}$ & 0.220091 & 316.93104 \\
$24 \mathrm{~h}$ & 0.355892 & 512.48448 \\
$36 \mathrm{~h}$ & 0.385716 & 555.43104 \\
$48 \mathrm{~h}$ & 0.344922 & 496.68768 \\
\hline
\end{tabular}

\section{3}

\section{CRRT in Pediatrics}

\author{
J.M. Park, J.S. Lee, S.Y. Ahn, J.I. Shin
}

Pediatrics, Yonsei University College of Medicine, Seoul, Korea

Objective: The purpose of this article is to describe the experience with PRISMA CRRT in critically ill pediatric patients. Methods: We reviewed our center's experience with continuous veno-venous hemodialysis (CVVHD) or CVVHDF (continuous veno-venous hemodiafiltration) since the pediatric program was established in 2003 March. Results: Nine children ( 4 girls, 5 boys) aged 6 months to 15 years (mean $5.5 \pm 4.4$, median 5 years) were treated with CVVHD or CVVHDF for a duration of 2-7 days (mean $4.1 \pm 2.3$, median 3 days). Weight ranged between 7.0 to $40.0 \mathrm{~kg}$ (mean $18.5 \pm 10.2$, median $18.0 \mathrm{~kg}$ ). Eight out of 9 patients were critically ill in the intensive care unit on ventilator support and cardiac support with pressors. Eight out of 9 patients were associated with the acute renal failure resulted in chemotherapy or bone marrow transplantation. One patient was not able to perform the peritoneal dialysis because of the ventral hernia. Anticoagulation were performed with heparin bolus with $10 \mathrm{ml} / \mathrm{kg}$ and continuous infusion with $10 \mathrm{ml} / \mathrm{kg} / \mathrm{min}$ in 8 patients and no heparin in one patient. Seven patients were expired because of severity of the underlying disease despite of the improvement of the renal failure. Conclusions: We conclude that CRRT in pediatrics is an efficient dialysis method. Because our patient numbers were small, we expect the use of this machine in pediatric patients will expand significantly in the future.

\begin{tabular}{llllrl}
\hline $\begin{array}{l}\text { Body } \\
\text { weight } \\
(\mathrm{kg})\end{array}$ & $\begin{array}{l}\text { Underlying } \\
\text { disease }\end{array}$ & Mode & $\begin{array}{l}\text { Blood } \\
\text { flow rate } \\
(\mathrm{ml} / \mathrm{min})\end{array}$ & $\begin{array}{l}\text { Dialysate } \\
\text { rate } \\
(\mathrm{ml} / \mathrm{h})\end{array}$ & $\begin{array}{l}\text { Duration } \\
(\text { days })\end{array}$ \\
\hline 25 & Hepatoblastom & CVVHDF & 80 & 800 & 2 \\
12 & Neuroblastoma & CVVHD & 50 & 400 & 2 \\
21 & Osteosarcoma & CVVHDF & 60 & 1,000 & 7 \\
15 & Lymphangioblastoma & CVVHDF & 60 & 600 & 2 \\
40 & Aplastic anemia & CVVHDF & 100 & 1,000 & 5 \\
7 & ESRD & CVVHD & 50 & 400 & 3 \\
7 & Wilms tumor & CVVHDF & 35 & 300 & 2 \\
18 & Hepatoblastoma & CVVHDF & 80 & 800 & 7 \\
22 & BMT & CVVHDF & 70 & 800 & 7 \\
\hline
\end{tabular}

\section{4 \\ Calcium Free Dialysate is not Essential for an Effective and Safe Regional Citrate Anticoagulation for Continuous Veno-Venous Hemodiafiltration}

\author{
M. Gupta, N.K. Wadhwa, J.P. Boglia, J. Bock, R. Bukovsky \\ SUNY, Stony Brook, New York, USA
}

Introduction: Current regional citrate anticoagulation protocols for continuous veno-venous hemodiafiltration (CVVHDF) use calcium free dialysate due to concerns of potential citrate toxicity. Earlier, our group has demonstrated the safety and efficacy of regional citrate anticoagulation for CVVHDF, using calcium-containing dialysate. 
Purpose: The current study was designed to evaluate the effect of calcium in the dialysate on the efficacy of citrate as a regional anticoagulant. Methods: Anticoagulant citrate dextrose - formula A (ACD-A) was initiated at $170 \mathrm{ml} / \mathrm{h}$ via a ' $\mathrm{Y}$ ' connection at the junction of a double lumen hemodialysis catheter and prefilter tubing of Gambro PRISMA M100 set with AN69 hemofilter. Blood flow rate was set at $100 \mathrm{ml} / \mathrm{min}$. The rate was adjusted to maintain postfilter ionized calcium (iCa) between $1.0-1.5 \mathrm{mg} / \mathrm{dL}$. Calcium chloride $(10 \%)$ was administered q6 hourly on prn basis to maintain systemic serum iCa more than $4.0 \mathrm{mg} / \mathrm{dL}$. PRISMASATE BGK 2/0 (Gambro, USA) with $2.5 \mathrm{mEq}$ of calcium chloride per liter was delivered at $500 \mathrm{ml} / \mathrm{h}$. Prefilter replacement fluid (sodium chloride $0.9 \%$ or $0.45 \%$ ) was infused at $1,200 \mathrm{ml} / \mathrm{h}$. The PRISMA M-100 set was changed every $96 \mathrm{~h}$. Effluent total calcium, ionized calcium and citrate were measured 1-hour post initiation of CVVHDF and then daily. Systemic and postfilter serum ionized calcium were measured 1-hour after initiating CVVHDF and then every six-hourly. Results: During the period of April 2003 to June 2003, 10 patients (4 females, 6 males) in intensive care units underwent citrate based CVVHDF using calcium-containing dialysate. CVVHDF was performed for a total of 59 days using 19 M100 sets. The mean hemofilter life span was $74.52+24.3 \mathrm{~h}$. The mean ACD-A infusion rate was $20.34+$ $1.24 \mathrm{mmol}$ of citrate per hour. None of the patients developed signs of citrate toxicity. The mean serum total calcium, systemic ionized calcium and postfilter ionized calcium were $7.4+0.83 \mathrm{mg} / \mathrm{dL}, 3.47+$ $0.28 \mathrm{mg} / \mathrm{dL}$ and $1.25+0.10 \mathrm{mg} / \mathrm{dL}$ respectively. The mean effluent total calcium, ionized calcium and citrate $1 \mathrm{~h}$ post initiation of CVVHDF were $4.83+0.37 \mathrm{mg} / \mathrm{dL}, 1.03+0.11 \mathrm{mg} / \mathrm{dL}$ and $701+$ $113 \mathrm{mg} / \mathrm{dL}$ respectively (compared to ionized calcium of $5.0 \mathrm{mg} / \mathrm{dL}$ in the dialysate at initiation). Hence, the filtered citrate chelated most of the free calcium in the dialysate within an hour post initiation of CVVHDF. In addition, the effluent mean ionized calcium remained lower (statistically significant) than the post filter mean ionized calcium at $1 \mathrm{~h}, 24 \mathrm{~h}$ and $48 \mathrm{~h}$ post initiation of CVVHDF. Conclusions: (1) Filtered citrate chelates most of the ionized calcium in the dialysate within an hour of initiation of CVVHDF. (2) The mean effluent ionized calcium remains significantly lower than the post filter mean ionized calcium. Hence, there is no net positive influx of ionized calcium from the dialysate to the blood. (3) The efficacy of citrate as a regional anticoagulant is not affected by the presence of calcium in the dialysate.

25

\section{Regional Citrate Anticoagulation in Continuous Hemodialysis and Extended Daily Dialysis: UCDMC Experience}

\author{
M.A. Craig, D. Love, J. Brass \\ University of California Davis Medical Center, \\ California, USA
}

Purpose: To provide Continuous Hemodialysis or Extended Daily Dialysis to acute renal failure patients in the ICU, who could not receive heparin anticoagulation. These patients were usually trialed on saline flushes, but would clot the dialytic system quickly, minimizing the effective dialysis and losing patient blood. Solution: We developed an order set and standard for Continuous Hemodialysis and
Extended Daily Dialysis with Regional Citrate Anticoagulation. Orders varied but included dialysis for 6-24h/day, blood flow rate of $100-200 \mathrm{ml} / \mathrm{min}$, dialysis flow rate of $100-300 \mathrm{ml} / \mathrm{min}$, and ultrafiltration of $0-500 \mathrm{ml} / \mathrm{h}$ as the patient needed and or tolerated. ACD-A (citrate solution) was infused (rate was proportionate to the blood flow rate) in the arterial chamber and anticoagulated the system by binding ionized Calcium, preventing the clotting cascade. This effect was reversed by infusing Calcium Gluconate at the port returning to the patient. The system ionized Calcium was maintained at $0.4-0.6 \mathrm{~mol} / \mathrm{L}$, while the patient ionized Calcium was kept at $1.17-1.31 \mathrm{~mol} / \mathrm{L}$ (normal range). These ionized Calcium are achieved by titrating the ACD-A and the Calcium Gluconate solution. The dialysate composition included Potassium of $3-4 \mathrm{mEq} / \mathrm{L}$, Calcium of 0 , Sodium of $135 \mathrm{mEq} / \mathrm{L}$, Bicarbonate of $25-30 \mathrm{mEq} / \mathrm{L}$, and Phosphorus of $0-2.5 \mathrm{mg} / \mathrm{dL}$. Outcomes: Regional Citrate Anticoagulation allowed us to provide either Extended Daily Dialysis or Continuous Hemodialysis to patients that had previously been difficult to dialyze. These regionally anticoagulated dialysis systems can last as long as $48 \mathrm{~h}$ when the system is discontinued for disinfection.

\section{6 \\ Study of Hemodynamic Disturbances during Slow Extended Daily Hemodialysis vs Continuous Renal Replacement Therapy in Acute Renal Failure Patients in the Intensive Care Unit I. Yegenaga', R. Vanholder ${ }^{2}$, E. Hoste $^{3}$, B. Van Vlem
, \\ ${ }^{1}$ Department of Internal Medicine, Kocaeli University Medical School, Turkey, ${ }^{2}$ Department of Internal Medicine, Nephrology Division, ${ }^{3}$ Department of Intensive Care, University Hospital of Ghent, Belgium}

The aim of the study was to compare the effect on hemodynamic disturbances, and practicality of slow extended daily dialysis (SLEDD) vs continuous renal replacement therapies in ICU patients. During a six months period, 12 consequent patients with ARF were randomized in one of the two therapeutic arms of the study. 5 patients were treated with SLEDD ( 2 female/ 3 male), mean age: $58.6+17.5$ and continuous therapy was applied in the other seven patients $(3 \mathrm{~F} / 4 \mathrm{M})$, mean age: $62.7+18.9(\mathrm{p}=\mathrm{ns})$. APACHE II scores were not significantly different between the two groups $(20.4+10.9$ vs $22.4+5.3$ respectively, $\mathrm{p}=\mathrm{ns}$ ). For the evaluation of hemodynamic stability, mean arterial blood pressure (MAP) values were obtained every $5 \mathrm{~min}$; in patients with SLEDD for an average of $18 \mathrm{~h}(9-24 \mathrm{~h})$, and 7 patients with CVVHD an average of $20 \mathrm{~h}(5-26 \mathrm{~h})$. A $15 \%$ drop from the mean pretreatment value was considered as a hypotensive episode. Results: During the follow-up period the SLEDD group experienced 146/982 (15\%) hypotensive episodes, vs 80/1,650 (5\%) for the CRRT group $(\mathrm{p}<0.001)$. If we exclude severe cases (APACHE II $>30$ ) and recalculate, differences became insignificant $46 / 1,451$ (3\%) vs 31/719 (4\%) respectively. Moreover vasopressor and colloid treatment was not significantly different between these two groups. Conclusions: SLEDD therapy seemed to be more effective and faster than continuous therapy in ARF patients in ICU. It is concluded 
that more hypotensive episodes in SLEDD therapy were as a result of the severity of cases rather then the procedure itself, since differences became insignificant, when severe cases (APACE II >30) were excluded from the both groups of patients. Moreover supportive therapy was not different during the two procedures. This study showed that during SLEDD therapy hemodynamic stability was not influenced as much as expected and gives more free time to the critically ill patients for necessary interventions and as a result it is more suitable for ARF patients ICU. Unless there are strict contraindications for SLEDD therapy, this procedure should be the first choice for ARF patients in the ICU.

\section{7 \\ A Modified Simple Citrate Protocol Effectively Provides for High Convective Clearance in Continuous Veno-Venous Hemodiafiltration}

\section{P.Y. Chen, R. Speer, A.J. To/wani \\ University of Alabama at Birmingham, Alabama, USA}

Background: We previously described a simple regional citrate protocol for continuous veno-venous hemodiafiltration (CVVHDF) with the Prisma system using $2 \%$ trisodium citrate (TSC) as the replacement fluid (rate of $250-400 \mathrm{ml} / \mathrm{h}$ ) and saline as the dialysate (rate of $1,000-1,500 \mathrm{ml} / \mathrm{h}$ ). Although the protocol is simple and effective, its disadvantage is its inability to provide high convective clearance. As a result we modified our protocol to a $0.67 \%$ TSC solution delivered as replacement fluid (RF) at $1,000-1,500 \mathrm{ml} / \mathrm{h}$ and a Bicarbonate- 25 dialysate $\left(\mathrm{Na}^{+} 140 \mathrm{mEq} / \mathrm{L}, \mathrm{HCO}_{3}^{-} 25 \mathrm{mEq} / \mathrm{L}, \mathrm{K}^{+}\right.$ $4.0 \mathrm{mEq} / \mathrm{L}$ ) delivered at $1,000-2,500 \mathrm{ml} / \mathrm{h}$. In this study we determine the efficacy on dialyzer patency of this protocol. Methods: This is a prospective study of dialyzer patency in 10 critically ill patients receiving CVVHDF with $0.67 \%$ Trisodium Citrate in predilutional mode using the Prisma and M100 pre-pump infusion set. All patients received a systemic calcium infusion. Acid-base status, electrolytes, and serum and postfilter ionized calcium were monitored along with frequency of dialyzer clotting. Dialyzers were routinely changed at $72 \mathrm{~h}$. Results: Ten patients, mean age $53 \pm 6.0$ years and mean weight $97 \pm 15 \mathrm{~kg}$, were treated with this protocol. All patients had acute renal failure with mean creatinine $4.1 \pm 1.3$ and mean Apache II score $26 \pm 7$. A total of 40 dialyzers were utilized with a total of 86 CVVHDF patient-days. The Kaplan-Meier curve for dialyzer survival demonstrated a $71 \%$ survival rate at $72 \mathrm{~h}$ and $75 \%$ at $48 \mathrm{~h}$ compared to a $57 \%$ survival rate at $48 \mathrm{~h}$ with our $2 \%$ citrate protocol. The mean postfilter ionized calciums were $0.27 \pm 0.09$. The mean ultrafiltration rate was $29 \pm 8 \mathrm{ml} / \mathrm{kg} / \mathrm{h}$ and mean $\mathrm{RF}$ rate was $1015 \pm 283 \mathrm{ml} / \mathrm{h}$. Conclusion: Modified $0.67 \%$ TSC delivered as the prefilter RF for CVVHDF allows for higher convective clearance and prolongs dialyzer patency.

\section{8}

\section{A Simple Trisodium Citrate Protocol that Provides Metabolic Control and High Solute Clearance in Continuous Renal Replacement Therapy}

M.B. Prendergast, J.C. Hey, R. Speer, A.J. Tolwani

University of Alabama at Birmingham, Alabama, USA

Background: Regional citrate anticoagulation with continuous veno-venous hemodiafiltration (CVVHDF) is safe and effective, but its use has been complicated by the lack of simplified protocols that provide both adequate anticoagulation and metabolic control at higher ultrafiltration rates. A simple protocol using a Bicarbonate-25 dialysate $\left(\mathrm{Na}^{+} 140 \mathrm{mEq} / \mathrm{L}, \mathrm{HCO}_{3}^{-} 25 \mathrm{mEq} / \mathrm{L}, \mathrm{K}^{+} 4.0 \mathrm{mEq} / \mathrm{L}\right)$, a $0.67 \%$ Trisodium Citrate $\left(\mathrm{Na}^{+} 140 \mathrm{mEq} / \mathrm{L}\right)$ replacement fluid (RF), and a systemic calcium infusion was instituted with the goal of providing adequate anticoagulation and metabolic control at higher dialysis doses, while decreasing pharmacy labor and risk of error associated with frequent customized solution changes. Methods: This is a retrospective analysis of the metabolic control achieved using CVVHDF with the PRISMA in 11 critically ill patients who received Bicarbonate- 25 dialysate and $0.67 \%$ Trisodium Citrate RF at UAB since August 2003. Patient demographics, electrolytes, and $\mathrm{pH}$, as well as dialysis parameters were reviewed. Results: Mean patient age was 53.6 years. Mean serum bicarbonate was $24.1 \mathrm{mEq} / \mathrm{L}$; mean $\mathrm{pH}$ was 7.4 (range 7.34-7.48). Dialysate flow rates ranged from $913 \mathrm{ml} / \mathrm{h}$ to $2,062 \mathrm{ml} / \mathrm{h}$ (mean $1,516 \mathrm{ml} / \mathrm{h}$ ); replacement flow rates ranged from $731 \mathrm{ml} / \mathrm{h}$ to $1,509 \mathrm{ml} / \mathrm{h}$ (mean $1,048 \mathrm{ml} / \mathrm{h}$ ). Rates were largely determined by desired dialysis dose. The mean ultrafiltration rate was $34.2 \mathrm{ml} / \mathrm{kg} / \mathrm{h}$. Serum ionized calciums were in the normal range and post filter ionized calciums were $<0.4 \mathrm{mmol} / \mathrm{L}$. Conclusion: The use of $0.67 \%$ Trisodium Citrate as both the anticoagulant and RF along with a Bicarbonate- 25 dialysate simplify the system with the advantage of providing convective clearance and metabolic control.

\section{9}

\section{Influence of Ultrafiltrate Production Rate on Sieving Coefficient (SC) in Continuous Veno-Venous Hemofiltration (CVVH)}
D.A. Pasko ${ }^{1,2}$, M.D. Churchwel/ ${ }^{1}$, B.A. Mueller ${ }^{1,3}$
${ }^{1}$ Department of Clinical Sciences, University of Michigan College of Pharmacy, ${ }^{2}$ CS Mott Children's Hospital, ${ }^{3}$ Department of Pharmacy Services, University Hospital, Michigan, USA

Background: Most published drug SC have been generated at ultrafiltrate rates of $1 \mathrm{~L} / \mathrm{h}$. Brunet et al. (AJKD 1999) suggested that solute SC changes with differing ultrafiltration rates. Purpose: Determine if changes in ultrafiltration rate influence SC during CVVH at two different ultrafiltration rates using a F70 (Fresenius) hemofilter. Methods: An in vitro bovine blood-based CVVH model was used to assess the SC of urea, creatinine, uric acid, gentamicin, 
vancomycin and albumin. Formed ultrafiltrate was re-infused into blood source and SC was determined at two different ultrafiltration rates of 1 and $3 \mathrm{~L} / \mathrm{h}$ after $1 \mathrm{~h}$ of CVVH. Each experiment was run 5 times with a new hemofilter. All solutes were analyzed by Cobas Integra $^{\circledR} 400$ Plus (Roche). Results: Ultrafiltration rates of $3 \mathrm{~L} / \mathrm{h}$ resulted in statistically significant lower mean \pm SD. SC for both small (urea, creatinine, uric acid) and middle (vancomycin) molecular weight solutes compared to SC values at $1 \mathrm{~L} / \mathrm{h}$. Albumin was never detectable in the ultrafiltrate (all albumin ultrafiltrate values $<0.653 \mathrm{mg} / \mathrm{dL})$. Conclusions: The $26 \%$ decline in vancomycin SC is substantially greater than the $4-6 \%$ decrement observed with small solutes when ultrafiltrate rate increases from $1 \mathrm{~L} / \mathrm{h}$ to $3 \mathrm{~L} / \mathrm{h}$. Tripling ultrafiltrate rate from 1 to $3 \mathrm{~L} / \mathrm{h}$ does not triple solute clearance, particularly for larger solutes. These findings may have relevance to assessing drug and middle molecular weight substance clearances achieved with high volume hemofiltration techniques.

\begin{tabular}{lllllll}
\hline $\begin{array}{l}\text { UF } \\
\text { rate }\end{array}$ & $\begin{array}{l}\text { Urea } \\
\text { SC }\end{array}$ & $\begin{array}{l}\text { Creatinine } \\
\text { SC }\end{array}$ & $\begin{array}{l}\text { Uric acid } \\
\text { SC }\end{array}$ & $\begin{array}{l}\text { Gent } \\
\text { SC }\end{array}$ & $\begin{array}{l}\text { Vanco } \\
\text { SC }\end{array}$ & $\begin{array}{l}\text { Albumin } \\
\text { SC }\end{array}$ \\
\hline $1 \mathrm{~L} / \mathrm{h}$ & $1.09 \pm 0.02$ & $1.07 \pm 0.01$ & $1.07 \pm 0.01$ & $0.85 \pm 0.02$ & $0.96 \pm 0.02$ & $\begin{array}{l}\text { None } \\
\text { detected }\end{array}$ \\
$3 \mathrm{~L} / \mathrm{h}$ & $1.02 \pm 0.01 *$ & $1.03 \pm 0.02 *$ & $1.01 \pm 0.03 *$ & $0.81 \pm 0.10$ & $0.71 \pm 0.02 * \begin{array}{l}\text { None } \\
\text { detected }\end{array}$ \\
$\begin{array}{l}\mathrm{SC} \% \\
\text { change }\end{array}$ & $-6.4 \%$ & $-3.7 \%$ & $-5.6 \%$ & $-4.7 \%$ & $-26 \%$ & $\begin{array}{l}\text { Not } \\
\text { applicable }\end{array}$ \\
\hline
\end{tabular}

*p-value $<0.05,3 \mathrm{~L} / \mathrm{h} \mathrm{SC}$ vs. $1 \mathrm{~L} / \mathrm{h} \mathrm{SC}$ for same solute.

\section{0 \\ Comparison of Diffusive and Convective Clearance with AN69 and Polysulfone Hemodiafilters in CVVH and CVVHD}

\author{
D.A. Pasko ${ }^{1,2}$, M.D. Churchwell ${ }^{1}$, B.A. Mueller ${ }^{1,3}$ \\ ${ }^{1}$ Department of Clinical Sciences, University of Michigan \\ College of Pharmacy, ${ }^{2}$ CS Mott Children's Hospital, \\ ${ }^{3}$ Department of Pharmacy Services, University Hospital, \\ Michigan, USA
}

Background: Matzke et al. (AAC 2000) found that hemofilter type influenced the CVVHD clearance of small molecules (urea, creatinine, ceftazidime), but the influence of hemofilter type on the clearance of middle molecular weight substances has not been assessed. Further, the relative contribution to CVVH clearance caused by hemodiafilter choice is not well established at relatively low ultrafiltrate production rates. We assessed two hemodiafilters in CVVH and CVVHD modes to determine the influence that hemodiafilter type makes on solute clearance. Methods: A bovine blood-based, in vitro CRRT model was used to assess the sieving coefficients (SC) and dialysate saturation coefficients (SA) of urea, creatinine, uric acid, gentamicin, vancomycin and albumin with two different hemodiafilters (F70, Fresenius and M60, Hospal). CVVH was run at an ultrafiltrate rate of $1 \mathrm{~L} / \mathrm{h}$. CVVHD was run at a dialysate flow of $2 \mathrm{~L} / \mathrm{h}$ for both filters. Blood flow was $200 \mathrm{~mL} / \mathrm{min}$ for all experiments and each experiment was run 5 times with a new hemodiafilter. Blood was sampled pre and post filter and ultrafiltrate/spent dialysate from the dialysate sampling port of the B.Braun Diapact ${ }^{\mathrm{TM}}$ tubing system. All solutes were analyzed by Cobas Integra ${ }^{\circledR} 400$ Plus (Roche).
Results: Mean \pm SD SA and SC tended to be higher with F70 than M60, with statistically significant differences seen with creatinine and gentamicin in CVVHD mode and with urea, creatinine, and vancomycin in CVVH mode. Conclusions: Differences exist in dialysate saturation coefficient and sieving coefficient for small and middle molecular weight substances between M60 and F70 hemodiafilters. When all other CVVH and CVVHD operating parameters are kept constant, choice between these two hemodiafilters can alter clearance in CRRT up to a $22 \%$ for vancomycin and $27 \%$ for gentamicin. For smaller solutes there was a less dramatic change in clearance.

\begin{tabular}{|c|c|c|c|c|c|}
\hline Filter/rate & Urea & Creatinine & Uric acid & Gentamicin & Vancomycin \\
\hline $\begin{array}{l}\text { M60 } \\
\text { CVVHD } \\
2 \mathrm{~L} / \mathrm{h} \mathrm{SA}\end{array}$ & $1.08 \pm 0.08$ & $0.95 \pm 0.04$ & Not done & $0.66 \pm 0.16$ & $1.12 \pm 0.12$ \\
\hline $\begin{array}{l}\text { F70 } \\
\text { CVVHD } \\
2 \mathrm{~L} / \mathrm{h} \mathrm{SA}\end{array}$ & $1.14 \pm 0.07$ & $1.05 \pm 0.08$ & Not done & $0.91 \pm 0.05^{*}$ & $1.44 \pm 0.32$ \\
\hline $\begin{array}{l}\text { M60 } \\
\text { CVVH } \\
1 \mathrm{~L} / \mathrm{h} \mathrm{SC}\end{array}$ & $1.03 \pm 0.01$ & $1.03 \pm 0.02$ & $1.05 \pm 0.02$ & $0.96 \pm 0.10$ & $0.76 \pm 0.03$ \\
\hline $\begin{array}{l}\text { F70 } \\
\text { CVVH } \\
1 \mathrm{~L} / \mathrm{h} \mathrm{SC}\end{array}$ & $1.09 \pm 0.02^{*}$ & $1.07 \pm 0.01^{*}$ & $1.07 \pm 0.01$ & $0.85 \pm 0.02$ & $0.96 \pm 0.02 *$ \\
\hline
\end{tabular}

$*_{p}<0.05$, F70 vs. M60 data within same CRRT mode.

\section{1 \\ Additional Potassium Requirements in Continuous Veno-Venous Hemodiafiltration Using Commercially Available Dialysates}

\author{
R. Speer, M. Taylor, A.J. Tolwani \\ University of Alabama at Birmingham, Alabama, USA
}

Background: Fluid composition and management are important parts of continuous renal replacement therapy (CRRT). Commercially available CRRT dialysates such as PrismaSate $^{\circledR}$ (Gambro) and Normocarb $^{\circledR}$ (Dialysis Solutions Inc.) have increased the accessibility of CRRT to those practices that do not want or cannot prepare custommade solutions. Although commercial solutions are available, the ideal electrolyte composition of CRRT solutions has yet to be determined. PrismaSate ${ }^{\circledR}$ is available as a ready to use $5 \mathrm{~L}$ bag and provides a bicarbonate concentration of $32 \mathrm{mEq} / \mathrm{L}$ with a potassium of either $2 \mathrm{mEq} / \mathrm{L}$ or $0 \mathrm{mEq} / \mathrm{L}$. Normocarb ${ }^{\circledR}$ is a concentrate bicarbonate solution that is mixed into a $3 \mathrm{~L}$ of sterile water and provides a final bicarbonate concentration of $35 \mathrm{mEq} / \mathrm{L}$ with potassium of $3 \mathrm{mEq} / \mathrm{L}$ or $0 \mathrm{mEq} / \mathrm{L}$. At the University of Alabama at Birmingham, we have used both PrismaSate ${ }^{\circledR}$ with potassium $2 \mathrm{mEq} / \mathrm{L}(2.0 \mathrm{~K})$ and Normocarb ${ }^{\circledR}$ supplemented with potassium $3 \mathrm{mEq} / \mathrm{L}(3.0 \mathrm{~K})$ for continuous veno-venous diafiltration (CVVHDF). We retrospectively studied the potassium requirements in 16 patients undergoing CVVHDF using either a $2.0 \mathrm{~K}$ or $3.0 \mathrm{~K}$ dialysate during the months of July and August 2003. Methods: Sixteen patients with oligo-anuric acute renal failure were treated with CVVHDF using a $2 \%$ trisodium citrate solution delivered as a prefilter replacement solution at a rate of $250-330 \mathrm{ml} / \mathrm{h}$ and a dialysate solution consisting of either a $2.0 \mathrm{~K}$ or $3.0 \mathrm{~K}$ bath at a rate of $1,000-1,500 \mathrm{ml} / \mathrm{h}$. Patient demographics, daily electrolytes, daily dialysis parameters, and daily potassium supplementation were 
recorded. Results: Of the 16 patients studied, 8 patients were treated with a $2.0 \mathrm{~K}$ dialysate, and 8 patients were treated with a $3.0 \mathrm{~K}$ dialysate. The mean citrate replacement fluid rate was $310 \mathrm{ml} / \mathrm{h}$ and mean dialysate rate was $1,094 \mathrm{ml} / \mathrm{h}$ (mean ultrafiltration rate of $20 \mathrm{ml} / \mathrm{kg} / \mathrm{h}$ ). The mean CRRT days were 8 . Thirteen of the 16 patients required additional intravenous or oral potassium supplementation after 3 days of initiating CRRT. The average amount of potassium supplementation was $80 \pm 45 \mathrm{mEq} /$ day. Conclusions: Both commercialized $2.0 \mathrm{~K}$ and $3.0 \mathrm{~K}$ dialysates resulted in the need for potassium supplementation over time to maintain normokalemia in patients on CRRT. We hypothesize that a $4.0 \mathrm{~K}$ bath would likely be more physiologic and warrants further investigation in order to optimize the development of commercialized CRRT dialysates.

\section{2}

\section{Citrate Anticoagulation Using the Kimal Hygieia Machine for Convective Hemofiltration in Children and Adolescents}

\section{B.H. Wilkins, D.N. Schell, S. Alexander \\ Pediatric Intensive Care Unit, The Children's Hospital at Westmead, Sydney, Australia}

Introduction: Citrate anticoagulation of hemofiltration circuitry is in widespread use with many different machines, circuits and filters. Its use has not been reported with the Hygieia machine, which is widely used in Europe, Australasia and Asia. Methods: A citrate protocol was developed and tested. Substitution fluid containing $40 \mathrm{mEq} / \mathrm{L}$ sodium citrate and $100 \mathrm{mmol} / \mathrm{L}$ sodium chloride was delivered pre-filter at a blood:citrate flow ratio of 5:1, blood flow $3-5 \mathrm{ml} / \mathrm{kg} / \mathrm{min}$, achieving urea clearance of $30-50 \mathrm{ml} / \mathrm{kg} / \mathrm{h}$. Calcium and magnesium were delivered into a separate cannula to maintain normal plasma levels. The Hygieia pumps filtrate, substitution fluid and dialysate in a truly volumetric way, so citrate delivery into the high pressure pre-filter segment is exact. It measures and calculates venous take-off pressure, venous return pressure, transmembrane pressure and resistance to blood flow through the filter, helping predict circuit failure and identifying the exact cause of circuit failure. Results: Three patients, age 5, 6 and 16, have been treated. Anion gap in the circuit blood was consistently $5-7 \mathrm{mEq} / \mathrm{L}$ greater than the patient's anion gap, whereas circuit ionised calcium fluctuated between 0.2 and $0.5 \mathrm{mmol} / \mathrm{L}$. Resistance to blood flow through the filter was always low. There was no visible clotting in the circuit or filter. Circuits/filters only failed because of venous catheter resistance or because of high transmembrane pressure. There was never any metabolic alkalosis even after 7 days continuous treatment. Citrate lock or hypocalcemia did not develop. Citrate substitution fluid delivery is not continuous - there is a $30 \mathrm{~s}$ pause after every $150 \mathrm{ml}$ while the volumetric chamber fills - but this has not affected filter life. Conclusion: All circuits ran successfully without complications and without systemic anticoagulation.

\section{Future Trends}

33

\section{Urea Exchange Efficacy during Un-Fractionated Heparin Anticoagulation versus Low Molecular Weight Heparin (Dalteparin) Anticoagulation in Continuous Veno-Venous Hemofiltration}

\author{
K.J. van Doorn, I. Hubloue, D. Verbeelen ${ }^{1}$ \\ Department of Intensive Care, 'Department of \\ Nephrology, AZ-VUB, Brussels, Belgium
}

Introduction: Un-fractionated heparin (UFH) is the anticoagulation of choice in continuous renal replacement therapy (CRRT). The aim of this trial was to compare the efficacy of urea exchange during continuous hemofiltration with un-fractionated heparin and low molecular weight heparin (dalteparin). Patients and Methods: Twenty-nine critically ill patients with ARF were enrolled in this prospective, controlled, single-centre, randomized clinical trial. CRRT was performed by continuous pump-driven veno-venous hemofiltration (CVVH) (Baxter, BM25) and a F70 polysulphone highflux hemofilter. Pump-driven blood flow in the extracorporeal circuit was maintained at $110 \mathrm{ml} / \mathrm{min}$. Post-dilution bicarbonate substitution infused of $1,000 \mathrm{ml} / \mathrm{h}(\mathrm{Qd})$. Anticoagulants were administered in the bloodline before the filter. The hemofilter systems were primed with normal saline. The vascular access was obtained via a 11.5-Fr double lumen hemodialysis catheter. Enrolled patients were randomly allocated into two groups. UFH was administered as: a bolus of 2,500 IU into the circuit at the commencement of hemofiltration; the exact dose was based on patients activated clotting time (ACT). In the dalteparin group, a 'fixed-dose' protocol based on patients body weight and platelet count was used. We divided the patients randomized for dalteparin (Fragminâ, Pharmacia) in two groups: Patients with platelet count $<100.000$ received a bolus injection of $70 \mathrm{IU} / \mathrm{kg}$ and after $2 \mathrm{~h}$ a continuous infusion of $12.5 \mathrm{IU} / \mathrm{kg} / \mathrm{h}$ and patients with platelet count $>100.000$ receiving a bolus injection of $70 \mathrm{IU} / \mathrm{h}$ and after $2 \mathrm{~h}$ a continuous infusion of $40 \mathrm{IU} / \mathrm{kg} / \mathrm{h}$. Anticoagulant activity was clinically evaluated by venous pressure monitoring and visual inspection of the pressure chamber. If the venous pressure rose 2 times above start level, the infusion dose was doubled. If bleeding occurred, with unchanged pressure, the dose was 50\% reduced. Demographic and clinical parameters of the patients were compared in both groups. Urea in the dialysate and in the blood plasma after every new replacement of dialysate bag was also sampled. Dialysis adequacy was evaluated by the U/P-ratio. Results: Twenty-nine patients were enrolled in this study, of which 14 were randomized for dalteparin and 15 for heparin. In the dalteparin group 12 of 14 patients died compared with 10 of 15 in the heparin group. In the dalteparin group mean age was 63.1 years old. Eight of them were male and 12 patients were diagnosed with a sepsis at start of the CVVH. In the UFH group the mean age was 69.8 years old, 9 of them were male and 10 patients in that population were in sepsis. There was no significant difference of these parameters in both groups. All other measured baseline characteristics in both groups were similar (Hematological: hemoglobin, white blood cell 
count, platelets, Renal function: urea, creatinine, Hepatic enzymes: LDH, AST, ALT, Coagulation parameters: PTT, aPTT, fibrinogen). APACHE III-score at admission and at start of the CVVH were not significant different in both groups. Mean filter life span was not significantly different in both groups. $(32.0 \pm 14.4 \mathrm{~h}$ in the UFHgroup and $30.5 \pm 13.5 \mathrm{~h}$ in the LMWH-group $\mathrm{p}=0.7879)$. There was no association between $\mathrm{Hb}$, platelet count and fibrinogen at the start of CVVH and filter survival. U/P-ratio (dalteparin) was $0.88 \pm 0.14$ compared with an U/P-ratio (heparin) of $0.96 \pm 0.07, \mathrm{p}<0.0001$ (Mann-Whitney U test). Discussion: The adequacy of solute removal during CRRT is determined by numerous treatment parameters. Our two patient groups were identical. The results of our study showed a significant lower urea exchange in patients dialysed with dalteparin. Although, urea exchange under dalteparin anticoagulation in postdilution CVVH, still exceeds $80 \%$, the use of low molecular weight heparin in CRRT needs critical examination. Heparin is cheaper and easy to monitor compared with low molecular weight heparin. For that reason, UFH remains our anticoagulant of choice for continuous replacement therapy in the ICU.

34

Safety and Efficacy of Nesiritide (B-Type Natriuretic Peptide) in Patients with Acute Congestive Heart Failure (CHF) and Hyponatremia

\author{
V.S. Mathur \\ University of California, San Franciso and Mathur \\ Consulting, Woodside, California, USA
}

Background: Hyponatremia in the setting of CHF is a marker of disease severity and portends a poor prognosis. Nesiritide reduces preload and after load and causes natriuresis and direct suppression of the renin-angiotensin-aldosterone axis. In clinical trials mean serum sodium (SNa) levels were normal and nesiritide did not significantly change those levels. Objective and Methods: To determine if use of nesiritide could favorably impact $\mathrm{SNa}$ in patients with acute $\mathrm{CHF}$ and hyponatremia and to evaluate it's safety in this population, a subset of patients with $\mathrm{SNa}<132 \mathrm{mEq} / \mathrm{L}$ was examined from a randomized, double-blind, placebo-controlled efficacy trial $(\mathrm{N}=127)$ [Colucci NEJM 2000;343:246-53]. For the purpose of this analysis results from the two nesiritide groups $(0.015$ and $0.030 \mathrm{mcg} / \mathrm{kg} / \mathrm{min})$ were pooled. During the first $6 \mathrm{~h}$ of the trial, patients were only administered nesiritide or placebo. Beyond $6 \mathrm{~h}$ all patients could receive standard therapy as clinically indicated. Results: Results are shown in the table. In hyponatremic CHF patients, nesiritide use was associated with improved hemodynamics, $\mathrm{SNa}$, urine output, and renal function. The incidence of hypotension was low and no episodes of hypotension occurred during the first $6 \mathrm{~h}$ of treatment. Conclusion: In hyponatremic CHF patients, nesiritide use appears to be associated with improved hemodynamics, $\mathrm{SNa}$, urine output, and renal function.

\begin{tabular}{|c|c|c|}
\hline & $\begin{array}{l}\text { Nesiritide } \\
(\mathrm{n}=12)\end{array}$ & $\begin{array}{l}\text { Placebo } \\
(\mathrm{n}=14)\end{array}$ \\
\hline Baseline serum sodium $(\mathrm{mEq} / \mathrm{L})$ & $130.5 \pm 2.2$ & $130.4 \pm 2.2$ \\
\hline Serum sodium day $2(\mathrm{mEq} / \mathrm{L})$ & $131.8 \pm 2.0$ & $131.5 \pm 3.5$ \\
\hline Serum sodium day $5(\mathrm{mEq} / \mathrm{L})$ & $133.7 \pm 1.5$ & $126.0 \pm 0.0$ \\
\hline Baseline serum creatinine $(\mathrm{mg} / \mathrm{dL})$ & $1.8 \pm 1.1$ & $1.2 \pm 0.5$ \\
\hline Serum creatinine day $2(\mathrm{mg} / \mathrm{dL})$ & $1.4 \pm 0.8$ & $1.2 \pm 0.4$ \\
\hline Serum creatinine day $5(\mathrm{mg} / \mathrm{dL})$ & $1.4 \pm 0.8$ & $1.4 \pm 0.2$ \\
\hline $\begin{array}{l}\text { Urine output/hour during } \\
\text { first } 6 \mathrm{~h}(\mathrm{~mL} / \mathrm{h})\end{array}$ & $99 \pm 80$ & $58 \pm 40$ \\
\hline Baseline PCWP (mmHg) & $29.8 \pm 7.0$ & $23.9 \pm 4.8$ \\
\hline Change in PCWP at $6 \mathrm{~h}(\mathrm{mmHg})$ & $-4.8 \pm 7.8$ & $+7.6 \pm 6.6$ \\
\hline Baseline RAP (mmHg) & $17.4 \pm 10.8$ & $16.0 \pm 6.1$ \\
\hline Change in RAP at $6 \mathrm{~h}(\mathrm{mmHg})$ & $-2.8 \pm 2.8$ & $+2.7 \pm 5.7$ \\
\hline $\begin{array}{r}\text { Baseline SVR } \\
(\text { dyn } \cdot \mathrm{s}) / \mathrm{cm}^{5}\end{array}$ & $1,664 \pm 712$ & $1,417 \pm 606$ \\
\hline $\begin{array}{l}\text { Change in SVR at } 6 \mathrm{~h} \\
(\mathrm{dyn} \cdot \mathrm{s}) / \mathrm{cm}^{5}\end{array}$ & $-268 \pm 492$ & $-86 \pm 659$ \\
\hline Baseline CO (L/min) & $3.3 \pm 1.1$ & $3.9 \pm 1.1$ \\
\hline Change in $\mathrm{CO}$ at $6 \mathrm{~h}(\mathrm{~L} / \mathrm{min})$ & $+0.5 \pm 0.7$ & $0 \pm 1.3$ \\
\hline Baseline SBP (mmHg) & $106.9 \pm 13.6$ & $105.7 \pm 17.2$ \\
\hline Change in SBP at $6 \mathrm{~h}(\mathrm{mmHg})$ & $-2.6 \pm 17.2$ & $+3.0 \pm 11.0$ \\
\hline Baseline median Aldo (ng/dL) & 23.0 & 24.0 \\
\hline Change in median Aldo at $6 \mathrm{~h}(\mathrm{ng} / \mathrm{dL})$ & -11.4 & +3.1 \\
\hline $\begin{array}{l}\text { Symptomatic/Asymptomatic } \\
\text { Hypotension during first } 24 \mathrm{~h} \\
\text { (number of patients) }\end{array}$ & $0 / 1$ & $0 / 1$ \\
\hline
\end{tabular}

All values are means $\pm \mathrm{SD}$, unless otherwise indicated. $\mathrm{PCWP}=$ pulmonary capillary wedge pressure; Aldo $=$ serum aldosterone; $\mathrm{CO}=$ cardiac output; $\mathrm{SBP}=$ systolic blood pressure; RAP $=$ right atrial pressure.

35

\section{Linking Continuous Renal Replacement Therapy (CRRT) with the Electronic Health Record}

\author{
T.A. Beech-Gauthier, M.L. Lee, C.A. McKenney \\ Toronto East General Hospital, Toronto, \\ Ontario, Canada
}

Implementing a new CRRT documentation system can be both challenging and rewarding when it is electronically interfaced to the patient's health record. Toronto East General Hospital (TEGH) would like to share it's success story as the first hospital in North America to build an interface between the Gambro Healthcare ${ }^{\circledR}$ PRISMA $^{\circledR}$ and the Cerner INet computerized documentation system. TEGH is a 370bed community based acute care hospital providing health care to a diverse population ranging through the lifespan. The Surgical Intensive Care Unit (SICU) provides care for post-operative patients requiring intensive monitoring following peripheral vascular, general abdominal and thoracic surgery. CRRT is the most common treatment modality utilized to treat acute renal failure in both the post-operative population as well critically ill medical patients in the SICU. As the hospital implemented a computerized documentation system it became evident interfacing parameters from the PRISMA ${ }^{\circledR}$ as well as cardiac and respiratory data into the electronic health record was fundamental in providing a more complete documentation system. In addition, this maximized the use of the Cerner product. Consequently, an interdisciplinary team of clinical experts collaborated with 
computer technologists (from in-house as well as vendors) to expand the available devices to include the PRISMA ${ }^{\circledR}$. Increased efficiency, completeness of documentation, accessibility of data for statistics and possible research were some of the considerations incorporated into the action plan. This presentation will discuss the old system, our goals for change, the collaborative approach to planning and implementing the new system as well as the benefits of adding this device to the existing ones.

\section{6 \\ Development of a Consolidated CRRT Program}

K.S. Hodge ${ }^{1}$, J. Willis', J. Dwyer ${ }^{2}$

${ }^{1}$ Clarian Health Partners - IU Campus, ${ }^{2}$ Clarian Health

Partners - Methodist Campus, Indianapolis, Indiana, USA

Purpose: The consolidation of three major hospitals into one entity created opportunities to closely examine medical and nursing practices. Adult CRRT practice occurred at two of the three institutions. Practice was explored and revealed that differences existed both within and between the various clinical areas providing CRRT. The goal was to develop a standardized 'best practice' Adult CRRT Program. Methods: One institution had an existing Adult CRRT Program responsible to present education to novice CRRT practitioners, evaluate the program and processes, and direct modifications to either the program or the processes. The first step to creating a combined program was to enhance the existing committee with additional team members to create equal representation. The result was the creation of a multidisciplinary team, which includes nephrologists, critical care, dialysis, and advanced practice nurses, clinical educators, clinical managers, pharmacists, and dieticians. The second step was to determine team objectives. The identified objectives were to standardize practice in the areas of tracking and monitoring therapy delivered (flowsheet development), prescribing CRRT (physician orders), bringing it all together (policy and procedure development and endorsement), and revising the CRRT education (novice and advanced classes, and annual competencies). After months of collaborative efforts, all team objectives were accomplished. The team meets quarterly to review education evaluations, discuss new knowledge and technologies, make decisions about practice changes, and make program and process modifications as needed. A quarterly newsletter 'The Filter' is distributed after each meeting to update all practitioners regarding CRRT practice issues. Summary: The Adult CRRT Program is comprised of a multidisciplinary, consolidated team with standardized practice components: flowsheet, physician orders, policy, and initial and ongoing education and competency activities. Outcomes: The Clarian CRRT Program produces high nurse satisfaction and patient management outcomes, setting a standard of care in Indianapolis. Presentation of this program at the Midwest CRRT Symposium in October 2003 generated discussion for program revisions at other facilities both within Indiana and in surrounding states. It is anticipated that this content will be equally valuable for participants attending The Ninth International Conference on Continuous Renal Replacement Therapies.

\section{7}

The Study of Treatment of Hepatic Failure Patients with Hyperbilirubinemia by Plasma Dialysis - A New Blood Purification Modality

\author{
D. Gong, D. Ji, B. Xu, B. Ren, Y. Liu, L. Li \\ Research Institute of Nephrology, Jinling Hospital, \\ Nanjing University School of Medicine, \\ Nanjing, P.R. China
}

Objective: To evaluate a new proposed blood purification modality - plasma dialysis about the effect of removing bilirubin, when used in treatment of hepatic failure patients with jaundice. Methods: Eleven patients diagnosed as hepatic failure and jaundice were involved in this study. Four of them were treated by high volume hemofiltration (HVHF) for $12 \mathrm{~h}, 3$ patients were treated by hemoperfusion (HP) using macroporous resin sorbents, the other four were treated by a new proposed modality - plasma dialysis (PD) for $6 \mathrm{~h}$. During PD, 4,000 $\mathrm{ml}$ frozen plasma was used circularly as dialysate at flow rate of $6,000 \mathrm{ml} / \mathrm{h}$, and BLS816G filters were used as dialyzers. Serum total bilirubin (TB), direct bilirubin (DB) and indirect bilirubin (IB) was monitored before and after treatment in all patients, During HVHF, ultrafiltration was examined for TB, DB and IB concentrations, and during PD, wasted plasma was also examined for these indices. Results: After 12-h treatment of HVHF, the mean reduction of serum $\mathrm{TB}, \mathrm{DB}, \mathrm{IB}$ is $10.4 \pm 4.2 \%, 10.0 \pm 6.3 \%$ and $10.1 \pm 7.5 \%$, respectively, and the concentration of TB, DB and IB in ultrafiltration is $3.33 \pm 0.96,1.98 \pm 0.81$ and $1.35 \pm 0.26 \mu \mathrm{mol} / \mathrm{L}$, respectively. After HP treatment, the mean reduction of serum TB, $\mathrm{DB}$ and IB is $14.4 \pm 3.2 \%, 14.4 \pm 4.0 \%$ and $14.8 \pm 3.2 \%$, respectively. After 6-h PD treatment, the mean reduction of serum TB, DB and IB is $21.5 \pm 5.3 \%, 20.5 \pm 2.9 \%$ and $24.1 \pm 14.0 \%$ respectively. Conclusion: The existing blood purification modalities such as HVHF and HP are inadequate in removing of serum bilirubin, and the new proposed modality plasma dialysis is more effective in removing of serum bilirubin.

\section{8 \\ Evidence for Reduced Systemic Exposure to Fenoldopam Following Local Renal Delivery Compared to Intravenous Delivery

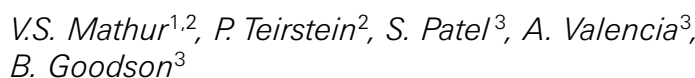 \\ 1 University of California, San Francisco and Mathur Consulting, Woodside, ${ }^{2}$ Scripps Clinic, San Diego, ${ }^{3}$ FlowMedica, Inc., Fremont, California, USA}

Objective: Renal ischemia and subsequent acute renal failure portend a poor prognosis. Systemic effects have limited the doses of renal vasodilator drugs such as atrial natriuretic peptide, dopamine, and fenoldopam. Fenoldopam has dose-dependent renal vasodilator effects, but doses that maximize renal blood flow are limited by 
Table 1: Fenoldopam dose $(\mathrm{mcg} / \mathrm{kg} / \mathrm{min})$ and route

\begin{tabular}{|c|c|c|c|c|}
\hline \multirow[t]{2}{*}{ Time (min) } & \multicolumn{4}{|c|}{ Fenoldopam plasma levels (ng/mL) } \\
\hline & $0.4 \mathrm{IV}$ & 0.4 IR & $0.8 \mathrm{IV}$ & $0.8 \mathrm{IR}$ \\
\hline \multicolumn{5}{|l|}{ Animal 1} \\
\hline Baseline & 0 & 0 & N/A & N/A \\
\hline 1 & 2.33 & 0 & 16.98 & 8.68 \\
\hline 3 & 4.20 & 1.18 & 18.66 & 10.42 \\
\hline 5 & 6.46 & 2.78 & 19.48 & 10.50 \\
\hline 30 & 9.84 & 5.29 & 24.31 & 12.96 \\
\hline 60 & 9.24 & 6.47 & 24.77 & 13.74 \\
\hline 120 & 10.90 & 5.61 & 21.48 & 14.64 \\
\hline 180 & 10.90 & 6.69 & 21.73 & 13.34 \\
\hline \multicolumn{5}{|l|}{ Animal 2} \\
\hline 0 & 0 & 0 & N/A & N/A \\
\hline 1 & 4.35 & 0.47 & 19.99 & 10.29 \\
\hline 3 & 6.31 & 2.7 & 22.96 & 12.21 \\
\hline 5 & 4.97 & 4.22 & 24.42 & 11.77 \\
\hline 30 & 12.61 & 6.34 & 29.97 & 15.45 \\
\hline 60 & 12.73 & 7.19 & 28.58 & 14.45 \\
\hline 120 & 14.36 & 6.74 & 31.84 & 16.79 \\
\hline 180 & 14.90 & 7.17 & 30.88 & 16.81 \\
\hline
\end{tabular}

hypotension, a particular concern in already hypotensive critically ill patients. We postulated that intra-renal (IR) infusion of fenoldopam should increase renal exposure and desired renal effects while reducing systemic exposure to the extent that drug is excreted by the kidneys on first pass. To our knowledge this is the first report of use of a renal vasodilator via bilateral IR delivery. Methods: Two anesthetized dogs received fenoldopam at doses of 0.4 and $0.8 \mathrm{mcg} / \mathrm{kg} / \mathrm{min}$ via continuous infusion intravenously (IV) and IR on two separate days one week apart. Each dose was administered for $180 \mathrm{~min}$ ( 6 half lives of fenoldopam in dogs). IR administration was accomplished through the FlowMedica Bifurcated Infusion Catheter, inserted via the femoral artery. Results: IR delivery of fenoldopam yielded approximately 50\% lower plasma levels than the same dose administered IV (table 1). Maximum \% decrease in systolic blood pressure on IV vs. IR treatment was $27 \%$ vs. $15 \%$ and $31 \%$ vs. $20 \%$ in animals 1 and 2, respectively. Conclusions: IR delivery of drugs intended to have renal effects but that are limited by systemic effects may prove to be a novel approach to treatment of a number of renal conditions such as acute renal failure, allograft rejection, and congestive heart failure. 
Ahn, S.Y. 23

Alexander, S. 32

Alexander, S.R. 8, 9

Amigues, L. 19

Baum, M. 8, 9

Beech-Gauthier, T.A. 35

Beraud, J.J. 19

Bhatt, U.Y. 3

Bissler, J.J. 18

Blowey, D. 8, 9

Bock, J. 24

Boglia, J.P. 24

Brass, J. 25

Brophy, P.D. 8, 9

Bukovsky, R. 24

Bunchman, T.E. 8, 9, 12

Canaud, B. 19

Cantaluppi, V. 14, 15

Chang, J.W. 7

Chen, P.Y. 27

Chua, A.N. 8, 9

Churchwell, M.D. 16, 29, 30

Colardyn, F. 26

Craig, M.A. 25

Deleuze, S. 19

Ding, Y.-T. 20

Doorn, K.J. van 33

Dwyer, J. 17, 36

Eding, D.M. 12

Fenocchio, C.M. 14, 15

Flores, F.X. 2, 8, 9

Fortenberry, J. 8, 9
Gardner, J.J. 12

Goldstein, S.L. 8, 9

Gong, D. 5, 6, 37

Goodson, B. 38

Gupta, M. 24

Hackbarth, R. 8, 9

Hackbarth, R.M. 12

Hemasilpin, N. 18

Hey, J.C. 28

Hiroshi, I. 13

Hodge, K.S. 17, 36

Hoste, E. 26

Hubloue, I. 33

Hughes, S.L. 4

Ikeda, K. 10

Ikeda, T. 10

Ito, S. 11

Ji, D. 5, 6, 37

Kinouchi, Y. 11

Klouche, K. 19

Koch, A.Z. 12

Kuroda, Y. 11

Kuroki, Y. 10

Lameire, N. 26

Lanfranco, G. 14

Lee, J.S. 23

Lee, M.L. 35

Lee, S.K. 7

Li, L. 5, 6, 37

Liu, Y. 37

Liu, Z. 5

Love, D. 25
Maccarielo, E. 1, 21, 22

Macy, A. 4

Mahan, J. 8, 9

Masahiro, T. 13

Massanet, P. 19

Mathur, V.S. 34, 38

Matsushita, M. 10

Maxvold, N.J. 12

McKenney, C.A. 35

Miyamoto, H. 11

Moscato, D. 15

Mueller, B.A. 16, 29, 30

Nagura, M. 10

Nitta, Y. 11

Ohnishi, Y. 11

Okahisa, T. 11, 13

Pacitti, A. 14, 15

Paiva, R.A.N. 1, 21, 22

Park, E.J. 7

Park, J.M. 23

Park, S.-K. 7

Pasko, D.A. 16, 29, 30

Patel, S. 38

Plott, D.T. 3

Podda, G. 14

Polycarpou, M.M. 18

Prendergast, M.B. 28

Ren, B. 6, 37

Rocha, E. 1, 21, 22

Rodrigues, M.G. 1, 21, 22

Ruzany, F. 1, 21, 22

Schell, D.N. 32

Segoloni, G.P. 14
Shin, J.I. 23

Somers, M.J.G. 8, 9

Song, H. 7

Song, M.-G. 7

Speer, R. 27, 28, 31

Suassuna, J.H. 1, 21, 22

Susumu, I. 13

Symons, J.M. 8, 9

Taniuchi, J. 10

Tao, J. 6

Taylor, M. 31

Teirstein, P. 38

Tolwani, A.J. 27, 28, 31

Vaj, M. 15

Valencia, A. 38

Valente, C. 1, 21, 22

Van Vlem, B. 26

Vanholder, R. 26

Veglio, V. 15

Verbeelen, D. 33

Wadhwa, N.K. 24

Wilkins, B.H. 32

Willis, J. 17, 36

Xie, H. 5

$\mathrm{Xu}$, B. 5, 6, 37

Yamkokoski, T. 3

Yang, W.S. 7

Yasuhiro, K. 13

Yegenaga, I. 26

Yoshiaki, O. 13

Zhang, M. 20 